\title{
Removal of Reactive Anionic Dyes from Binary Solutions by Adsorption onto Quaternized Kenaf Core Fiber
}

\author{
Intidhar Jabir Idan, ${ }^{1,2}$ Siti Nurul Ain Binti Md. Jamil, ${ }^{3}$ \\ Luqman Chuah Abdullah, ${ }^{1,4}$ and Thomas Shean Yaw Choong ${ }^{1}$ \\ ${ }^{1}$ Department of Chemical and Environmental Engineering, Faculty of Engineering, Universiti Putra Malaysia, Selangor, Malaysia \\ ${ }^{2}$ Department of Environmental Engineering, Faculty of Engineering, University of Babylon, Babylon, Iraq \\ ${ }^{3}$ Department of Chemistry, Faculty of Science, Universiti Putra Malaysia, Selangor, Malaysia \\ ${ }^{4}$ Institute of Tropical Forestry and Forest Product (INTROP), Universiti Putra Malaysia, Selangor, Malaysia
}

Correspondence should be addressed to Intidhar Jabir Idan; immb2010@yahoo.com

Received 4 November 2016; Revised 2 January 2017; Accepted 11 January 2017; Published 8 March 2017

Academic Editor: Subrata Mondal

Copyright (C) 2017 Intidhar Jabir Idan et al. This is an open access article distributed under the Creative Commons Attribution License, which permits unrestricted use, distribution, and reproduction in any medium, provided the original work is properly cited.

\begin{abstract}
The most challenging mission in wastewater treatment plants is the removal of anionic dyes, because they are water-soluble and produce very shining colours in the water. In this regard, kenaf core fiber (KCF) was chemically modified by the quaternized agent (3-chloro-2-hydroxypropyl)trimethylammonium chloride to increase surface area and change the surface properties in order to improve the removing reactive anionic dyes from binary aqueous solution. The influencing operating factors like dye concentration, $\mathrm{pH}$, adsorbent dosage, and contact time were examined in a batch mode. The results indicate that the percentage of removal of Reactive Red-RB (RR-RB) and Reactive Black-5 (RB-5) dyes from binary solution was increased with increasing dyes concentrations and the maximum percentage of removal reached up to $98.4 \%$ and $99.9 \%$ for RR-RB and RB-5, respectively. Studies on effect of $\mathrm{pH}$ showed that the adsorption was not significantly influenced by $\mathrm{pH}$. The equilibrium analyses explain that, in spite of the extended Langmuir model failure to describe the data in the binary system, it is better than the Jain and Snoeyink model in describing the adsorption behavior of binary dyes onto QKCF. Also, the pseudo-second-order model was better to represent the adsorption kinetics for RR-RB and RB-5 dyes on QKCF.
\end{abstract}

\section{Introduction}

Environmental pollution due to speedy development of industries causes harmful effect on human health and ecosystem. The textile dyeing industries have generated a massive pollution problem because it is considered one of the most industries which used a wide range of dyes in their production. Consequently, it is the most polluting water sources [1].

It is estimated that every year 280,000 tones of textile dyes are released in textile mill effluent [2], and unfortunately, all factories are still using water streams for discharging their effluent water. However, the necessity for the renewal of our water resources has received growing interest. This has led up to the evolution of strategies to the reversion of water to its source in the least possible pollution form, to enable using water again. These strategies and processes are termed as "wastewater treatment" [3].

Although the colour is not included in the Environment Conservation Rules which was published in 1997, it is an issue in dye effluent because, unlike other pollutants, it is so visible. Consequently, international textile industries are increasingly setting discharge standards for colour [4].

The use of commercial activated carbon for removing dyes is expensive as it is obtained from nonrenewable starting materials like lignite, coal, and petroleum coke. Therefore, aqueous phase adsorption by utilizing different types of agroresidues is one of the most alternatives materials for removing different types of dyes (including reactive dyes) from wastewater [5].

Agricultural biomass can be procured either directly from plant species or indirectly from a processing of domestic, 
TABLE 1: Binary adsorption studies for the removal of reactive dyes from aqueous solution.

\begin{tabular}{|c|c|c|c|}
\hline Binary dye system & Adsorbent & $\begin{array}{l}\text { Adsorption } \\
\text { capacity, } q_{e} \\
\text { (mg/g) }\end{array}$ & Reference \\
\hline $\begin{array}{l}\text { Remazol Black B } \\
\text { Remazol Red }\end{array}$ & Wheat straw & $\begin{array}{l}2.1 \\
2.5\end{array}$ & {$[11]$} \\
\hline $\begin{array}{l}\text { Reactive Remazol Red F-3B } \\
\text { Remazol Blue }\end{array}$ & $\begin{array}{l}\text { Coconut coir } \\
\text { activated carbon }\end{array}$ & $\begin{array}{c}2.01 \\
12.19\end{array}$ & {$[12]$} \\
\hline $\begin{array}{l}\text { Reactive Black-5, } \\
\text { Reactive Red E }\end{array}$ & $\begin{array}{c}\text { Palm kernel } \\
\text { shell-activated carbon }\end{array}$ & - & {$[13]$} \\
\hline $\begin{array}{l}\text { Reactive Orange 16, } \\
\text { Basic Blue } 3\end{array}$ & Sugar cane bagasse & $\begin{array}{l}34.48 \\
37.59\end{array}$ & {$[14]$} \\
\hline $\begin{array}{l}\text { Reactive Orange 16, } \\
\text { Methylene Blue }\end{array}$ & Modified rice husk & $\begin{array}{l}1.829 \\
4.958\end{array}$ & {$[15]$} \\
\hline $\begin{array}{l}\text { Reactive Red, } \\
\text { Reactive Blue }\end{array}$ & Activated carbon & $\begin{array}{l}3.01 \\
1.45\end{array}$ & {$[16]$} \\
\hline $\begin{array}{l}\text { Reactive Blue 2, } \\
\text { Eriochrome Black T }\end{array}$ & $\begin{array}{l}\text { Chitosan-based } \\
\text { hydrogel }\end{array}$ & $\begin{array}{l}47.8 \\
58.9\end{array}$ & [9] \\
\hline $\begin{array}{l}\text { Reactive Orange } 12 \\
\text { Direct Yellow } 12\end{array}$ & $\begin{array}{c}\text { ZnS:Mn } \\
\text { nanoparticles loaded } \\
\text { on activated carbon }\end{array}$ & - & {$[17]$} \\
\hline $\begin{array}{l}\text { Reactive Orange } \\
\text { Basic Blue } 3\end{array}$ & Modified rice hull & $\begin{array}{l}- \\
-\end{array}$ & {$[8]$} \\
\hline
\end{tabular}

commercial, industrial, or agricultural products. Around the world, an enormous amount of agricultural residues is producing every year. Disposal of these agricultural residues have generated a secondary environmental pollution. This increases the researchers' interest to produce porous adsorbent which can be derived from renewable, abundant, and low-cost substances generated from an agricultural origin [6].

Many agricultural wastes and natural adsorbents have been tested for the removal of the dyes from textile effluents [7]. Lee et al. [8] studied the removal of Basic Blue-3 (BB3) and Reactive Orange-16 (RO16) dyes from single and binary systems using ethylenediamine modified rice hull. The results showed that the sorption of both dyes was $\mathrm{pH}$ and concentration-dependent. The uptake of BB3 was favored at high $\mathrm{pH}$ whereas that of $\mathrm{RO} 16$ was favored at low $\mathrm{pH}$.

Oladipo et al. [9] studied the removal of Reactive Blue 2 and Eriochrome Black $\mathrm{T}$ dyes from single and binary solution by adsorption on chitosan-based hydrogel. It was observed that the maximum adsorption capacity for Reactive Blue 2 and Eriochrome Black $\mathrm{T}$ in binary solution was 47.8 and $58.9 \mathrm{mg} / \mathrm{g}$, respectively. The recent reports in the removing reactive dyes from binary system are tabulated in Table 1.

However, limited studies have been reported to transform these agricultural residues to a suitable adsorbent for commercial application to remove dyes by using batch adsorption system [10].

In the present research, kenaf core fiber (KCF) residual was chemically modified with (3-chloro-2-hydroxypropyl)trimethylammonium chloride (CHPTAC) to alter the surface properties and increase surface area to develop more active sites to capture dyes from solution.

To date, the utilization of quaternized kenaf core fiber (QKCF) to adsorb binary reactive dyes has not been reported elsewhere. In the present work, the mechanism of dyes adsorption onto QKCF was studied to provide engineering information (e.g., uptake capacities and equilibrium time) to develop an adsorption design. The constants parameters that were obtained from equilibrium data of single dye were utilized to predict the binary adsorption behavior of dyes.

\section{Materials and Methods}

2.1. Preparation Adsorbent from Kenaf Core Fibers. KCF was obtained from Institute of Tropical Forestry and Forest Product (INTROP) in Universiti Putra Malaysia. KCF coarse powder was sieved using $1 \mathrm{~mm}$ and $0.25 \mathrm{~mm}$ stainless steel sieves to get particles with size range from $0.25 \mathrm{~mm}$ to $1 \mathrm{~mm}$. The sieved kenaf particles were washed a few times with tap water to get rid of dust and undesirable particles. The KCF powder was rinsed with distilled water and dried in an oven for 24 hours at $50^{\circ} \mathrm{C}$.

The KCF was mercerized by soaking it in a solution of $6.25 \mathrm{mmol}$ of $\mathrm{NaOH}$ for 24 hours. The basic medium swelled the fibers walls and opened the pores to improve KCF absorbency. Mercerized KCF (MKCF) was washed with distilled water and dried in an oven at $50^{\circ} \mathrm{C}$ for 24 hours.

The quaternization was accomplished by reacting each gram of dried MKCF with a solution consisting of $1.5 \mathrm{~g}$ of $\mathrm{NaOH}, 6.67 \mathrm{~mL}$ of (3-chloro-2-hydroxypropyl)trimethylammonium chloride (CHPTAC) solution (60 wt $\%$ in water), and $2.5 \mathrm{~mL}$ of water. The mixture was well-kept in a closed container at room temperature for 24 hours. Then, the quaternized kenaf core fiber (QKCF) was washed with $0.1 \%$ acetic acid solution to halt the reaction and rinsed with distilled water until neutral condition was achieved. Then, 
TABLE 2: General properties of reactive dyes.

\begin{tabular}{lcc}
\hline Commercial name & Reactive Red-RB & Reactive Black-5 \\
Chemical name & Reactive Red 198 & Remazol Black B \\
$\lambda_{\text {max }}(\mathrm{nm})$ & 288 & 599 \\
Molecular weight $(\mathrm{g} / \mathrm{mol})$ & 967.5 & 991.82 \\
Chemical formula & $\mathrm{C}_{27} \mathrm{H}_{18} \mathrm{C}_{1} \mathrm{~N}_{7} \mathrm{Na}_{4} \mathrm{O}_{15} \mathrm{~S}_{5}$ & $\mathrm{C}_{26} \mathrm{H}_{21} \mathrm{~N}_{5} \mathrm{Na}_{4} \mathrm{O}_{19} \mathrm{~S}_{6}$ \\
\hline
\end{tabular}<smiles>[M]OS(=O)(=O)OCCS(=O)(=O)OCCS(=O)(=O)c1ccc(N=Nc2c(S(=O)(=O)OCCS(=O)(=O)O[Al])cc3c(c2O)C(N)C(N=Nc2ccc(S(=O)(=O)O[Na])cc2)=C(S(=O)(=O)O[Na])C3)cc1</smiles>

(a)

(b)

FIGURE 1: Molecular structure of (a) Reactive Red-RB and (b) Reactive Black-5.

QKCF was dried at $50^{\circ} \mathrm{C}$ for 24 hours and kept in a closed container prior to use.

Fourier Transform-Infrared (FT-IR) Spectrometer 100 (PerkinElmer- precisely, United Kingdom) was used to record Infrared (IR) spectra. FT-IR spectrum was used in this study to identify the characteristic functional groups in QKCF.

Scanning Electron Microscope (SEM) (Hitachi Model S$3400 \mathrm{~N}$ ) was used to investigate the structure morphologies of QKCF. The SEM was registered at a magnification of $100 \mu \mathrm{m}$ and the instrument was turn on at $15 \mathrm{kV}$.

2.2. Preparation of Dyes Solution. Reactive Red-RB (RR$\mathrm{RB}$ ) and Reactive Black-5 (RB-5) dyes were utilized as adsorbates in the present study. The structures of these two dyes and the general properties of selected reactive dyes are presented in Figure 1 and Table 2, respectively. Stock solutions of $1000 \mathrm{mg} / \mathrm{L}$ of dyes were prepared, respectively, by dissolving $1.00 \mathrm{~g}$ of dye in $1 \mathrm{~L}$ distilled water. Solutions of various concentrations were prepared by diluting the stock solutions.

2.3. Single Adsorption Isotherm Studies. Adsorption isotherm for single-component solution was studied by using $250 \mathrm{~mL}$ Erlenmeyer flasks. The volume of dye was $100 \mathrm{~mL}$ in each flask, and the initial dyes concentrations for singlecomponent solution were $100 \mathrm{mg} / \mathrm{L}$. The dosage of QKCF was varying from 0.05 to $0.16 \mathrm{~g} / 100 \mathrm{~mL}$. All flasks were fully closed using aluminum foil to prevent evaporation and leakage. The incubator shaker was set at $200 \mathrm{rpm}, 25^{\circ} \mathrm{C}$, and 24 hours. The liquid and adsorbents were separated by using fast filter paper. The change in dye concentration in each solution was determined using a spectrophotometer UV-1800 (Shimadzu, Japan). The concentration of each dye was measured at maximum wavelength $\left(\lambda_{\max }\right) 288 \mathrm{~nm}$ and $599 \mathrm{~nm}$ for the RR-RB and RB-5, respectively. The adsorption capacity at equilibrium condition, $q_{e}(\mathrm{mg} / \mathrm{g})$ was calculated using (1) and a dye removal percentage was calculated by using (2).

$$
\begin{array}{r}
q_{e}=\left(C_{o}-C_{e}\right) \frac{V}{W} \\
\% \text { Removal }=\frac{C_{o}-C_{e}}{C_{o}} * 100,
\end{array}
$$

where $C_{o}$ and $C_{e}$ represent the initial and final dye concentrations (mg/L), respectively, $W$ represents the weight of QKCF (g), and $V$ refers to the volume of dye solution $(L)$ [18].

2.4. Binary Adsorption Studies. In binary systems, the ratio of mixing for each sample was $1: 1$, which mean that every $100 \mathrm{~mL}$ of dyes solution was prepared by mixed $50 \mathrm{~mL}$ of RR$\mathrm{RB}$ dye with $50 \mathrm{~mL}$ of RB-5 dye. The concentration of each dye was changed depending on the experiments.

To investigate the influence of dye concentration on the removal efficiency of RR-RB in the presence of RB5 dye, a varying concentration of RR-RB range from 25$100 \mathrm{mg} / \mathrm{L}$ was mixed with a fixed concentration of RB-5 $(25 \mathrm{mg} / \mathrm{L}$ or $100 \mathrm{mg} / \mathrm{L})$. In order to investigate the effects of dye concentration on the removal efficiency of RB-5 in the presence of RR-RB dye, a varying concentration of RB-5 range from $25-100 \mathrm{mg} / \mathrm{L}$ was mixed with a fixed concentration of RR-RB (25 mg/L or $100 \mathrm{mg} / \mathrm{L})$. For all the experiments, three different $\mathrm{pH}(4,6$, and 8$)$ were used and $0.1 \mathrm{~g}$ of QKCF dosage was added to each flask.

To investigation the effects of initial dye concentration, the two dyes were mixed with an equal concentration range from 20-200 mg/L. One g/L QKCF was added to each flask. 


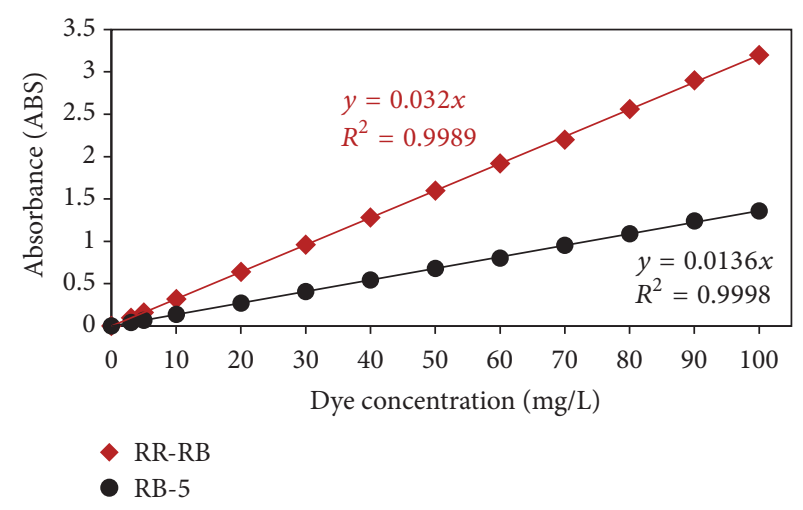

(a)

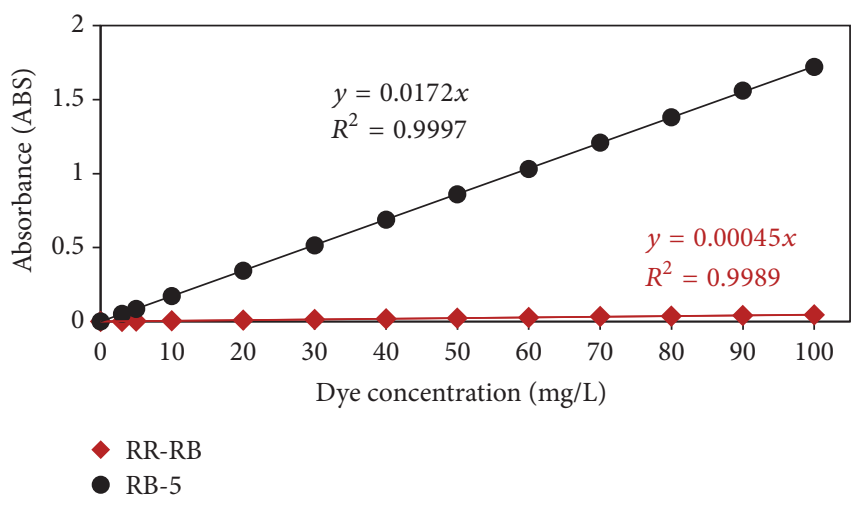

(b)

FIgURE 2: Calibration curves for RR-RB and RB-5 dyes at (a) $\lambda_{\max }=288 \mathrm{~nm}$ and (b) $\lambda_{\max }=599 \mathrm{~nm}$.

The study of the effect of adsorbent dosage was carried out at different weight of QKCF ranging from 0.05 to $0.25 \mathrm{~g} / 100 \mathrm{~mL}$ while the concentrations of dyes in multicomponent are ranging from 25 to $100 \mathrm{mg} / \mathrm{L}$.

Adsorption isotherm for a multicomponent solution was studied by using the same procedure flowed in single component and the dye concentration in multicomponent was kept constant at $100 \mathrm{mg} / \mathrm{L}$.

The study of the effect of contact time was achieved by varying the dye concentrations in multicomponent from 20 to $100 \mathrm{mg} / \mathrm{L}$. The samples were withdrawn at increasing contact time intervals ranging from $15 \mathrm{~min}$ to $180 \mathrm{~min}$. From this study, the kinetics of adsorption was determined.

2.5. Measurement of Dye Concentration in Multicomponent Solution. UV-spectrophotometer method is the common procedure for determination of the dye concentration in their mixture. To achieve that, linear relation between absorbance $(A)$ and concentration of dye $(C)(\mathrm{mg} / \mathrm{L})$ which was given by Beer-Lambert law in (3) was applied [19].

$$
A=K C+E,
$$

where

$A$ is absorbance of light at a maximum wave length $\left(\lambda_{\max }\right)$;

$K$ is the absorbance coefficient (slope of linear relation);

$C$ is the concentration of dye in solution $(\mathrm{mg} / \mathrm{L})$;

$E$ is the intercept of a linear relation.

For binary system, the total absorbance $A 1$ at $\lambda_{1 \max }$ will be the sum of absorbance of the individual components $R$ and $B$, which can be written as

$$
A 1=k R 1 * C R+k B 1 * C B .
$$

Similarly, for $A 2$ that was measured at $\lambda_{2 \max }$ it can be written as

$$
A 2=k R 2 * C R+k B 2 * C B
$$

The combination of above equations results in (6) and (7), respectively. Equations (6) and (7) provide the values for the concentration of each component, CR (RR-RB) and CB (RB$5)$.

$$
\begin{aligned}
& C R=\frac{(k R 2 * A 1-k B 1 * A 2)}{(k R 1 * k B 2-k R 2 * k B 1)} \\
& C B=\frac{(k R 1 * A 2-k R 2 * A 1)}{(k R 1 * k B 2-k R 2 * k B 1)},
\end{aligned}
$$

where $k R 1, k B 1, k R 2$, and $k B 2$ represent the calibration constants for dyes RR-RB and RB-5 at wavelengths $288 \mathrm{~nm}$ and $599 \mathrm{~nm}$, respectively.

Therefore, to calculate the dye concentrations of each dye in binary solution, four calibration curves were built to determine four calibration coefficients using pure standards dyes of RR-RB and RB-5 of known concentration as illustrated in Figure 2. As shown in Figure 2, the calibration constants for $\mathrm{RR}-\mathrm{RB}$ and RB-5 are

$$
\begin{aligned}
K R 1 & =0.032, \\
k B 1 & =0.0136
\end{aligned}
$$

measured at $\lambda 1 \max =288 \mathrm{~nm}$

$$
\begin{aligned}
& k R 2=0.00045, \\
& k B 2=0.0172
\end{aligned}
$$

measured at $\lambda 2 \max =599 \mathrm{~nm}$.

So, the concentrations of RR-RB and RB- 5 dyes were calculated depending on

$$
\begin{aligned}
& C R=\frac{((0.0172 * A 1)-(0.0136 * A 2))}{((0.032 * 0.0172)-(0.00045 * 0.0136))} \\
& C B=\frac{((0.032 * A 2)-(0.00045 * A 1))}{((0.032 * 0.0172)-(0.00045 * 0.0136))} .
\end{aligned}
$$

\section{Results and Discussion}

3.1. Characterization of Adsorbent. The FT-IR spectra of NKCF and QKCF are shown in Figure 3. QKCF has 


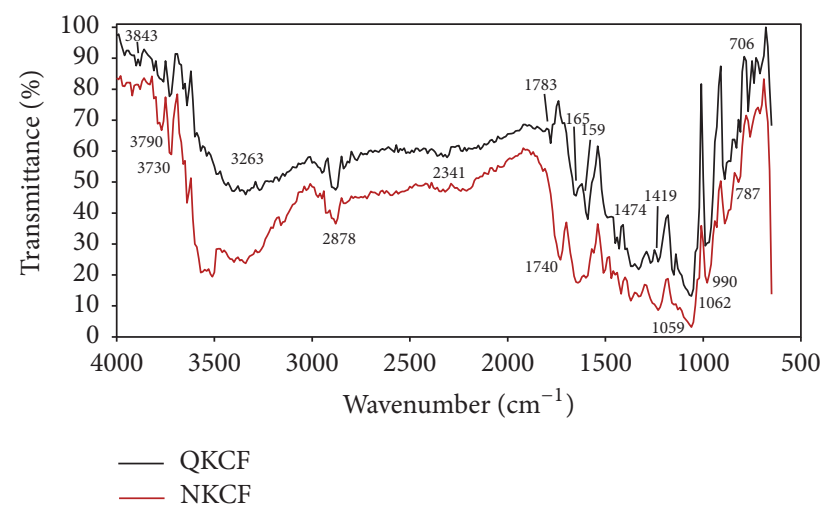

FIGURE 3: FT-IR spectra for NKCF and QKCF.

absorption bands at $2878 \mathrm{~cm}^{-1}$ and $2341 \mathrm{~cm}^{-1}$ which correspond to the stretching vibrations of $\mathrm{O}-\mathrm{H}$ and stretching of $\mathrm{C}-\mathrm{H}$, respectively. The absorption bands at $1783 \mathrm{~cm}^{-1}$, $1654 \mathrm{~cm}^{-1}$, and $1592 \mathrm{~cm}^{-1}$ on QKCF spectrum are assigned to aromatic $\mathrm{C}=\mathrm{C}$ stretch [20]. Furthermore, peaks at $1474 \mathrm{~cm}^{-1}$ and $1419 \mathrm{~cm}^{-1}$ that are assigned to $\mathrm{C}-\mathrm{H}$ stretching of tertbutyl group are an evidence of successful reaction between quaternary ammonia and QKCF. C-O stretch mode in C$\mathrm{O}-\mathrm{C}$ cellulose linkage appeared at $1059 \mathrm{~cm}^{-1}$ and $1062 \mathrm{~cm}^{-1}$ for $\mathrm{NKCF}$ and QKCF, respectively. The bands at QKCF and NKCF from $787 \mathrm{~cm}^{-1}$ to $706 \mathrm{~cm}^{-1}$ are assigned to $\mathrm{CH}_{2}$ rocking.

SEM is a primary tool for characterizing the surface morphology and fundamental physical properties of the adsorbent surface. The textural structures of granular natural KCF (NKCF), mercerized KCF (MKCF), and quaternized KCF (QKCF) were observed by SEM images (Figure 4). Figure 4(c) shows that the enlargement pores had turned into crevices and reveal native cellulose and more native cellulose; thus the previously unreachable interior part of the fiber was able to react with dye [21]. Furthermore, larger pores are more suitable for adsorption of bulky substrates such as reactive dyes [22].

BET analysis revealed that the surface area (SBET) increased from $2 \mathrm{~m}^{2} / \mathrm{g}$ for NKCF to $4 \mathrm{~m}^{2} / \mathrm{g}$ for QKCF. The average pore diameter of NKCF is $106 \mathrm{~nm}$, and QKCF has an average pore diameter of $283 \mathrm{~nm}$. Enlargement of the pore size is due to the dissolved lignin and hemicellulose in $\mathrm{NaOH}$ solution during the mercerization process. Furthermore, pore volume slightly decreased from $0.1699 \mathrm{~cm}^{3} / \mathrm{g}$ for NKCF to $0.1128 \mathrm{~cm}^{3} / \mathrm{g}$ for QKCF. It is attributed to the smoother texture of KCF surface after chemical quaternization.

3.2. Effect of Initial Dye Concentration. Figures 5(a) and 5(b) show the effect of initial RR-RB dye concentrations on the removal percentages of RR-RB dye onto QKCF while maintaining the concentration of RB-5 dye concentrations at $25 \mathrm{mg} / \mathrm{L}$ (Figure 5(a)) and $100 \mathrm{mg} / \mathrm{L}$ (Figure 5(b)), respectively. The $\mathrm{pH}$ of the adsorption systems were adjusted to $\mathrm{pH}$ 4,6 , and 8 to investigate the effect of $\mathrm{pH}$ on the removal percentages of RR-RB dye by QKCF adsorbent.
RR-RB dye removals were increased from $93 \%$ of removal up to $98 \%$ of removal as the initial RR-RB dye concentrations were increased from $25 \mathrm{mg} / \mathrm{L}$ up to $100 \mathrm{mg} / \mathrm{L}$ (Figure 5(a)). On the other hand, Figure 5(b) shows that the RR-RB dye removals were increased from $91.5 \%$ of removal up to $97.5 \%$ of removal as the concentrations of RR-RB dye were increased from $25 \mathrm{mg} / \mathrm{L}$ to $100 \mathrm{mg} / \mathrm{L}$. In addition, Figure 5 revealed that the removal percentages of RR-BB were almost similar although the initial concentrations of RB-5 were adjusted from $25 \mathrm{mg} / \mathrm{L}$ (Figure 5(a)) to $100 \mathrm{mg} / \mathrm{L}$ (Figure 5(b)).

Figures 6(a) and 6(b) show the effect of initial RB5 dye concentrations to the removal percentages of RB-5 dye onto QKCF while fixing the concentration of RR-RB dye concentrations at $25 \mathrm{mg} / \mathrm{L}$ (Figure 6(a)) and $100 \mathrm{mg} / \mathrm{L}$ (Figure 6(b)), respectively. The $\mathrm{pH}$ of the adsorption systems were adjusted to $\mathrm{pH} 4,6$, and 8 to investigate the effect of $\mathrm{pH}$ on the removal percentages of RB-5 dye by QKCF adsorbent. Figure 6(b) shows that RB-5 dye removals were increased from $98.5 \%$ to $99.5 \%$ as the initial RB-5 dye concentrations were increased from $25 \mathrm{mg} / \mathrm{L}$ up to $100 \mathrm{mg} / \mathrm{L}$. On the other hand, Figure 6(b) shows that the RB-5 dye removals were fixed around $99.5 \%$ as the concentrations of RB-5 dye were increased from $25 \mathrm{mg} / \mathrm{L}$ up to $100 \mathrm{mg} / \mathrm{L}$. In addition, Figure 6 revealed that the removal percentages of RB- 5 were almost similar although the initial concentrations of RR$\mathrm{RB}$ were adjusted from $25 \mathrm{mg} / \mathrm{L}$ (Figure 6(a)) to $100 \mathrm{mg} / \mathrm{L}$ (Figure 6(b)).

The variation of $\mathrm{pH}(\mathrm{pH} 4,6$, and 8$)$ in adsorption system for both cases (Figures 5 and 6) resulted in identical trend of dyes removal. This indicates that the adsorption of reactive dyes onto QKCF is not influenced by the $\mathrm{pH}$ of the adsorption system.

In RR-RB and RB-5 binary dye systems, RB-5 generally presented preferable adsorption on QKCF (Figure 7). A higher concentration of both dyes in solution would result in further dyes adsorption on the QKCF due to the fact that increase in the initial dye concentrations causes increase in the driving force to overcome the resistance of the mass transfer of dye between the solution and the adsorbent surface [23].

3.3. Effect of Adsorbent Dosage. The percentage of removals of RR-RB and RB-5 in a binary system is shown in Figure 8. Generally, in all cases (Figures 8(a), 8(b), 8(c), and 8(d), resp.) the removal percentage of RR-RB dyes was decreased as the doses of adsorbent were increased from $0.05 \mathrm{mg} / 100 \mathrm{~mL}$ up to $0.25 \mathrm{mg} / 100 \mathrm{~mL}$. This might be due to the less availability of $\mathrm{RR}-\mathrm{RB}$ and RB- 5 dyes to be adsorbed by the increasing active sites of adsorbent.

3.4. Effect of Contact Time. Figure 9 shows the effect of contact time on the removal of RR-RB in the presence of RB-5 in binary system. It was shown that, at various concentrations of dyes (20 mg/L up to $100 \mathrm{mg} / \mathrm{L}$ ), the RR-RB dye was rapidly adsorbed in the first $60 \mathrm{~min}$ of contact time and reached equilibrium at $\sim 100 \mathrm{~min}$ of contact time. Similar trend was revealed in the case of binary system for the removal of $\mathrm{RB}$ 5 dye in the presence of RR-RB dye (Figure 10). The rapid 


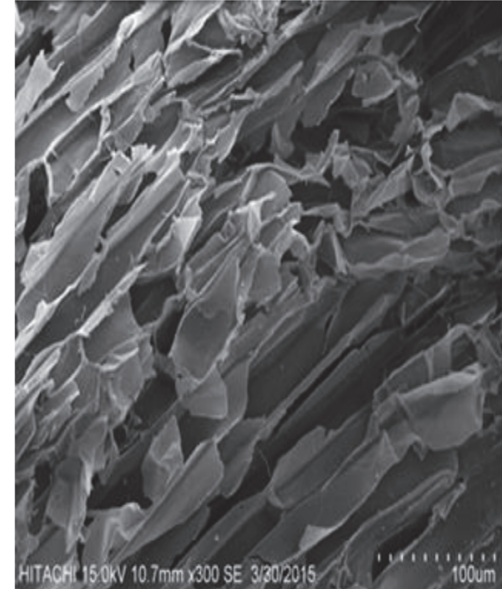

(a)

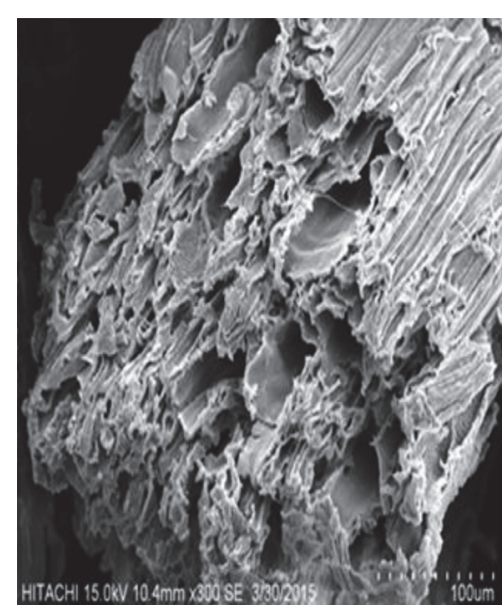

(b)

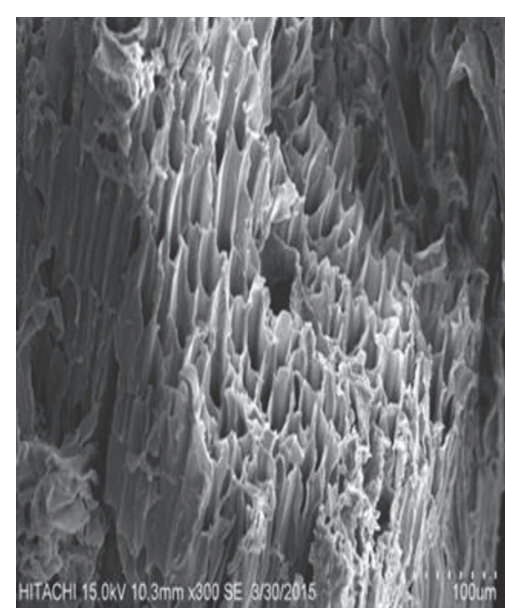

(c)

FIGURE 4: SEM images: (a) natural KCF, (b) mercerization KCF, and (c) quaternization KCF.

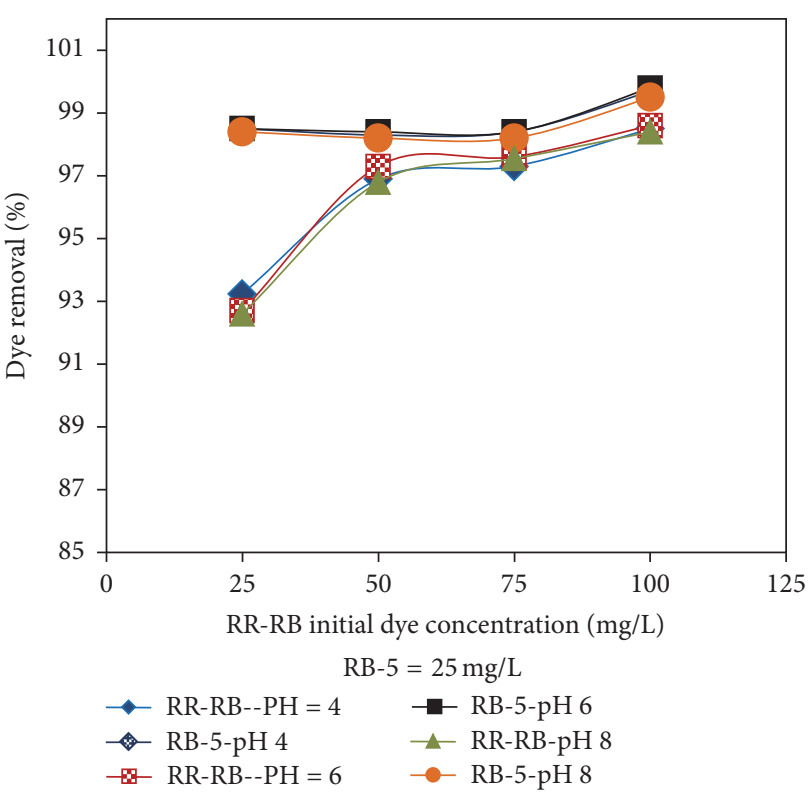

(a)

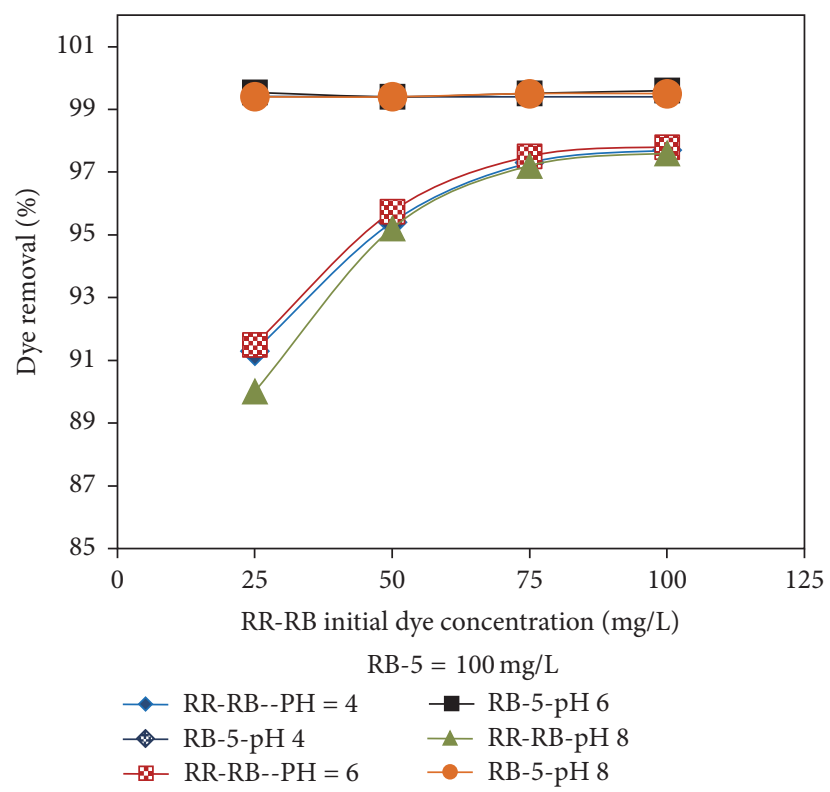

(b)

FIGURE 5: Effect of initial RR-RB dye concentrations on the removal percentages of RR-RB dye by QKCF at different $\mathrm{pH}$ in the presence of (a) $25 \mathrm{mg} / \mathrm{L}$ of RB-5 dye and (b) $100 \mathrm{mg} / \mathrm{L}$ of RB-5 dye (QKCF dosage $=0.1 \mathrm{~g} / 100 \mathrm{~mL}$, agitation speed $=200 \mathrm{rpm}$, time $=4 \mathrm{hr}$., and temp. $\left.=25^{\circ} \mathrm{C}\right)$.

adsorption at the initial 60 min of contact time might be due to the adsorption by the outer surface of the adsorbent. As the active sites of an exterior layer of the adsorbent have been fully saturated, the dyes were exerted into the pores of the adsorbent and occupied the interior layer of the adsorbent. The adsorption onto the active sites at the interior layer took a longer time to be completed before equilibrium was achieved [24]. In addition, as shown in Figures 9 and 10, the maximum dye removals were achieved as the concentrations of dyes were maximum $(100 \mathrm{mg} / \mathrm{L})$ in both cases. Meanwhile, the minimum dyes removals were obtained as the concentrations of dyes were minimum $(20 \mathrm{mg} / \mathrm{L})$ in both binary systems. This might be due to the fact that increase in initial dye concentration enhances the interaction between dye and adsorbent [25].

3.5. Adsorption Isotherms for Single System. Adsorption isotherms are basic requirements for any adsorption systems design. To quantify the adsorption capacity of adsorbents for the removal of adsorbate from aqueous solution, the equilibrium of a solute separated between liquid and solid phase is demonstrated by different models of adsorption 


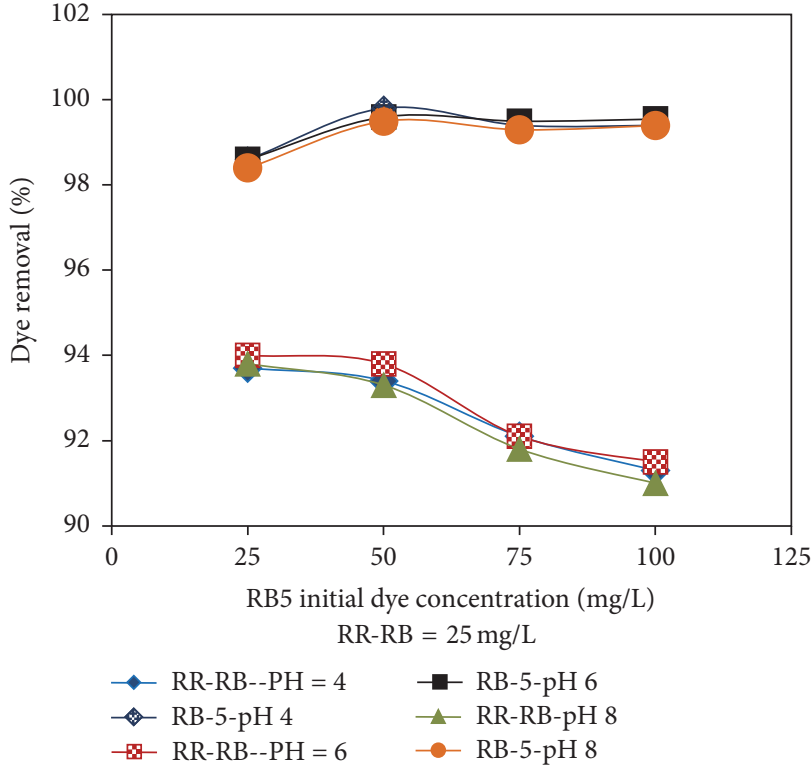

(a)

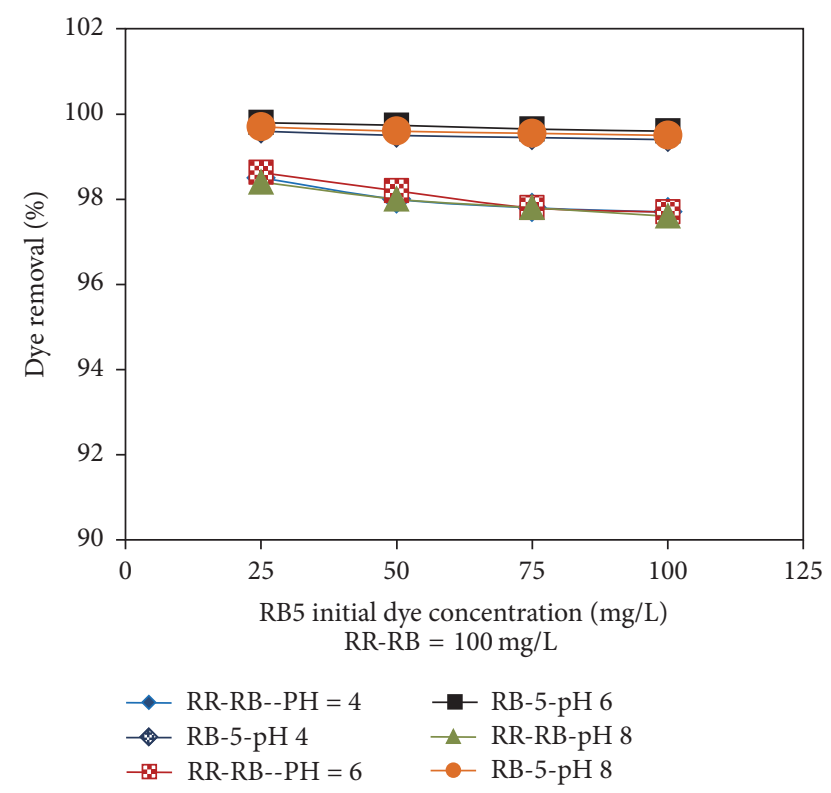

(b)

FIGURE 6: Effect of initial RB-5 dye concentrations on the removal percentages of RB-5 dye by QKCF at different $\mathrm{pH}$ in the presence of (a) $25 \mathrm{mg} / \mathrm{L}$ of RR-RB dye and (b) $100 \mathrm{mg} / \mathrm{L}$ of RR-RB dye (QKCF dosage $=0.1 \mathrm{~g} / 100 \mathrm{~mL}$, agitation speed $=200 \mathrm{rpm}$, time $=4 \mathrm{hr}$., and temp. $=$ $\left.25^{\circ} \mathrm{C}\right)$.

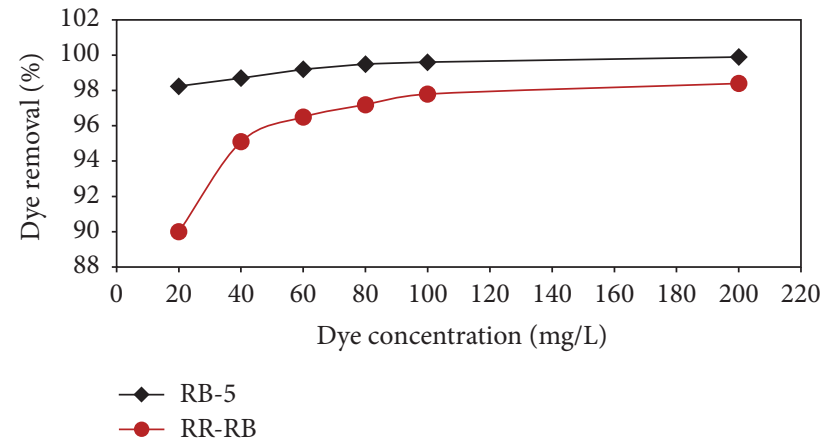

FIGURE 7: Effect of equal initial RR-RB and RB-5 dyes concentration on the removal efficiency of both dyes in binary system $(\mathrm{QKCF}$ dosage $=0.1 \mathrm{~g} / 100 \mathrm{~mL}$, agitation speed $=200 \mathrm{rpm}$, time $=3 \mathrm{hr}$, and temp. $\left.=25^{\circ} \mathrm{C}\right)$.

TABLE 3: Langmuir isotherm constants for RB-5 and RR-RB on QKCF in single system.

\begin{tabular}{lcccc}
\hline \multirow{2}{*}{ Dyes in single system } & \multicolumn{4}{c}{ Langmuir constants } \\
& $q_{\max }(\mathrm{mg} / \mathrm{g})$ & $b(\mathrm{~L} / \mathrm{mg})$ & $K_{L}(\mathrm{~L} / \mathrm{g})$ & $R^{2}$ \\
\hline RB-5 & 270.3 & 0.9024 & 243.9 & 0.95 \\
RR-RB & 169.5 & 0.444 & 75.2 & 0.992 \\
\hline
\end{tabular}

isotherms. One of these adsorption isotherms is Langmuir isotherm model. The applicability of the isotherm equations was a comparison by referring to the correlation coefficient, $R^{2}$ [26]. Langmuir model is characterized by the conditions that each site can take in only one molecule and adsorption energy is the same at all sites. In addition, the adsorbed molecules cannot move across the surface or react with neighboring molecules [27]. This model is given by (10) and the linearization form of Langmuir's model is given by (11) [28].

$$
\begin{aligned}
q_{e} & =\frac{q_{\max } b C_{e}}{1+b C_{e}} \\
\frac{C_{e}}{q_{e}} & =\frac{1}{b q_{\max }}+\frac{C_{e}}{q_{\max }},
\end{aligned}
$$

where $q_{e}$ is the amount of adsorbate dye per unit mass of adsorbent weight of QKCF at equilibrium $(\mathrm{mg} / \mathrm{g}), q_{\max }$ $(\mathrm{mg} / \mathrm{g})$ is a constant related to the area occupied by a monolayer of adsorbate, reflecting the maximum adsorption capacity, $b(\mathrm{~L} / \mathrm{mg})$ is a direct measure of the intensity of the sorption, and $C_{e}$ is the equilibrium concentration in the solution $(\mathrm{mg} / \mathrm{L})$. A plot of $C_{e} / q_{e}$ versus $C_{e}$ results in a straight line of slope $\left(1 / q_{\max }\right)$ and an intercept of $\left(1 / b q_{\max }\right)$.

The equilibrium adsorption isotherms for RR-RB and RB5 dyes adsorption onto QKCF are shown in Figures 11 and 12, respectively, and the isotherms parameters are calculated and presented in Table 3.

3.6. Adsorption Isotherms for Binary System. The equilibrium adsorption isotherms parameters for RR-RB and RB-5 dyes adsorption onto QKCF in binary experimental system are shown in Table 4. As can be observed from Table 4, the maximum adsorption capacity $\left(q_{\max }\right)$ for binary dye solutions was found to be smaller than $q_{\max }$ in single solution. This can be explained by the fact of competition and interaction between two dyes in binary system. 


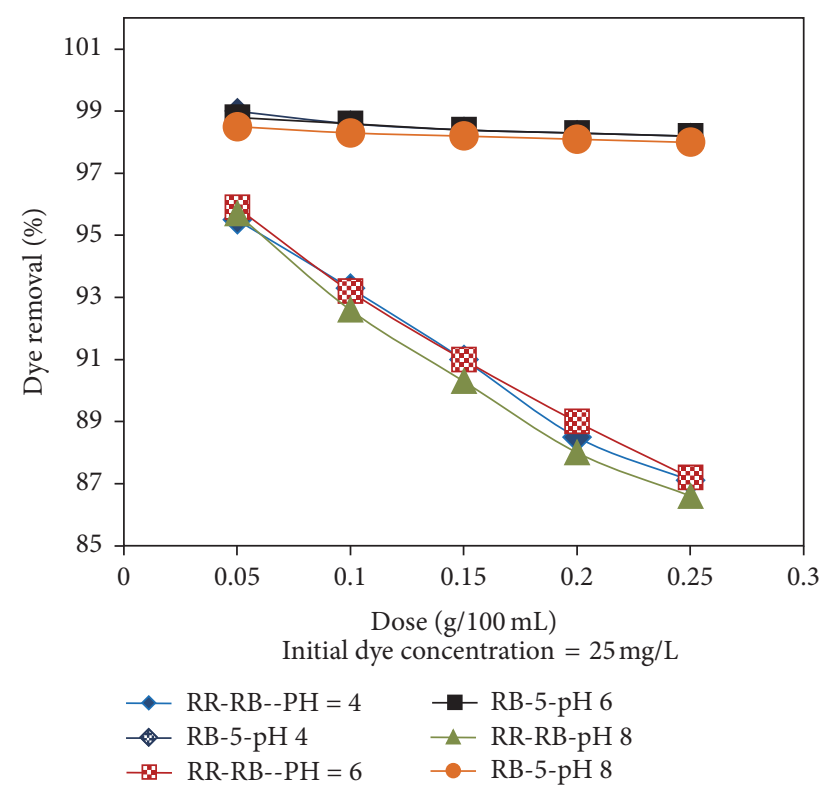

(a)

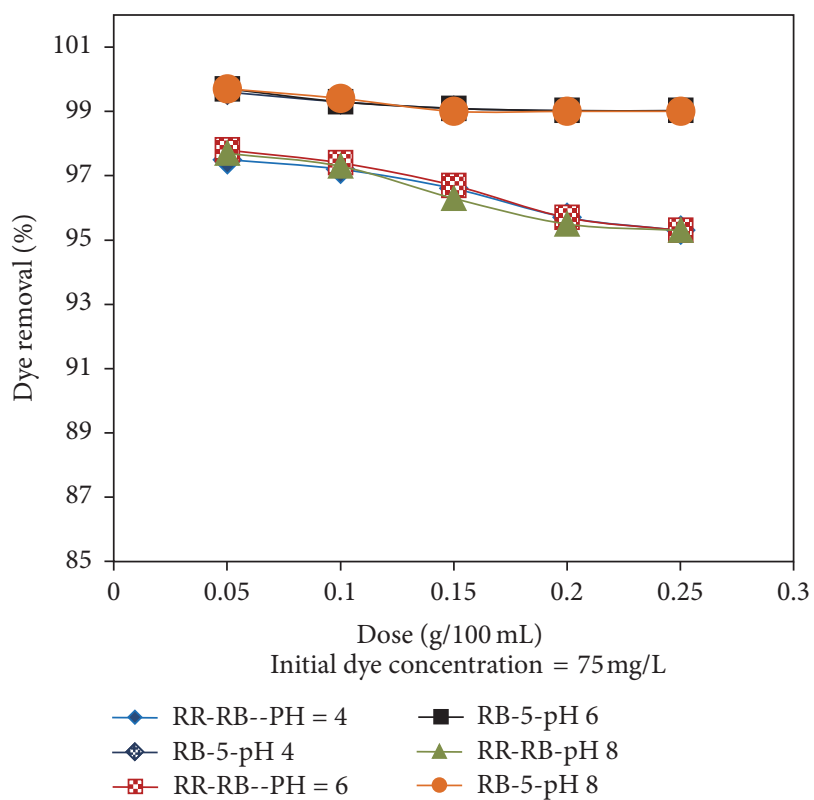

(c)

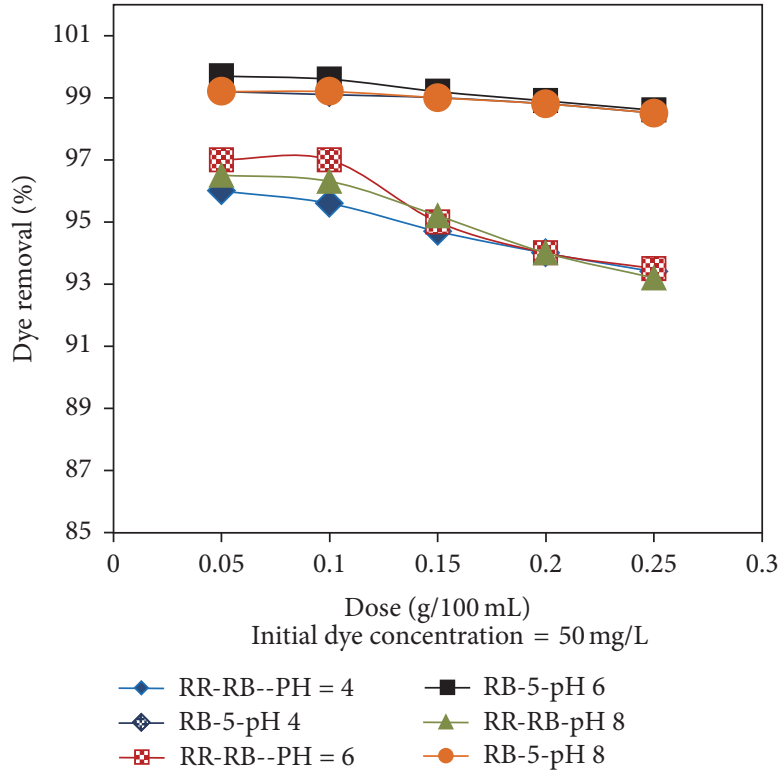

(b)

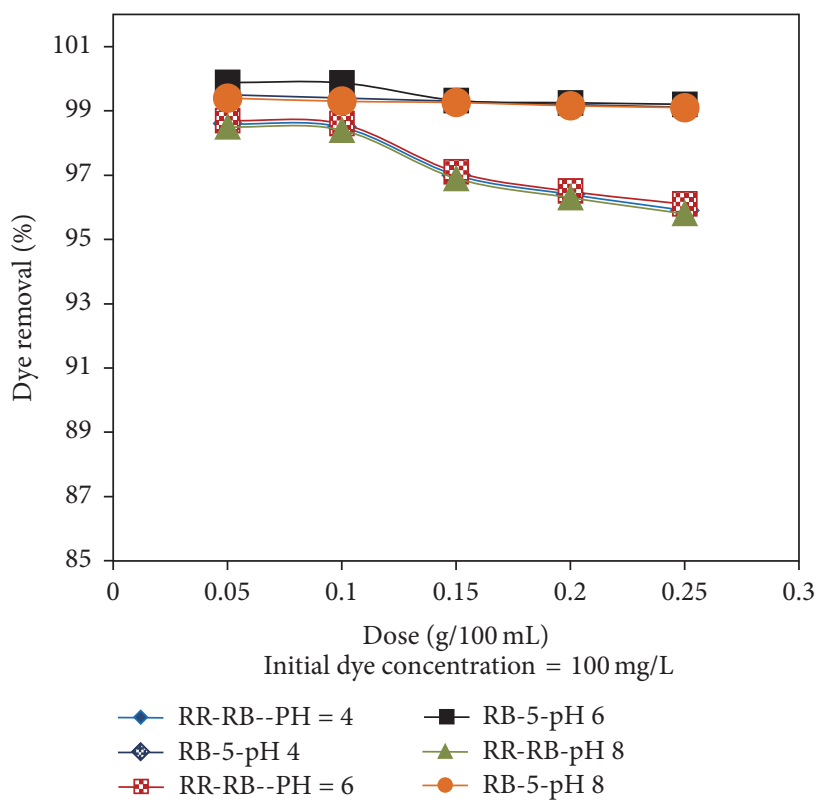

(d)

Figure 8: Effect of different adsorbent dosages in binary system with (a) $25 \mathrm{mg} / \mathrm{L}$ initial concentrations of RR-RB and RB-5, (b) 50 mg/L initial concentrations of RR-RB and RB-5, (c) $75 \mathrm{mg} / \mathrm{L}$ initial concentrations of RR-RB and RB-5, and (d) $100 \mathrm{mg} / \mathrm{L}$ initial concentrations of $\mathrm{RR}-\mathrm{RB}$ and RB-5 (temperature $=25^{\circ} \mathrm{C}$, agitation speed $=200 \mathrm{rpm}$, and adsorption time $=4 \mathrm{hr}$.).

3.6.1. Extended Langmuir Equation (ELE). The Langmuir model can be extended for binary system dye to give (12). This model was first developed by Butler and Ockrent [29]; they assumed that all the sites are equivalent, each site can hold at most one molecule of dye 1 or one molecule of dye 2 but not both, and there are no interactions between adsorbate molecules on adjacent sites.

$$
q_{i}=\frac{q_{\max , i} b_{i} C_{e, i}}{1+\sum_{i=1}^{n} b_{i} C_{e, i}} .
$$

For binary system the above equation becomes

$$
\begin{aligned}
& q_{1}=\frac{q_{\mathrm{max}, 1} b_{1} C_{e, 1}}{1+b_{1} C_{e, 1}+b_{2} C_{e, 2}} \\
& q_{2}=\frac{q_{\mathrm{max}, 2} b_{2} C_{e, 2}}{1+b_{1} C_{e, 1}+b_{2} C_{e, 2}},
\end{aligned}
$$

where $q_{1}$ and $q_{2}$ are the amounts of dyes 1 and 2 adsorbed per unit weight of sorbent at equilibrium concentrations of dyes $C_{e 1}$ and $C_{e 2}$ in a binary solution, respectively. $q_{\max , 1}$ and $q_{\max , 2}$ 


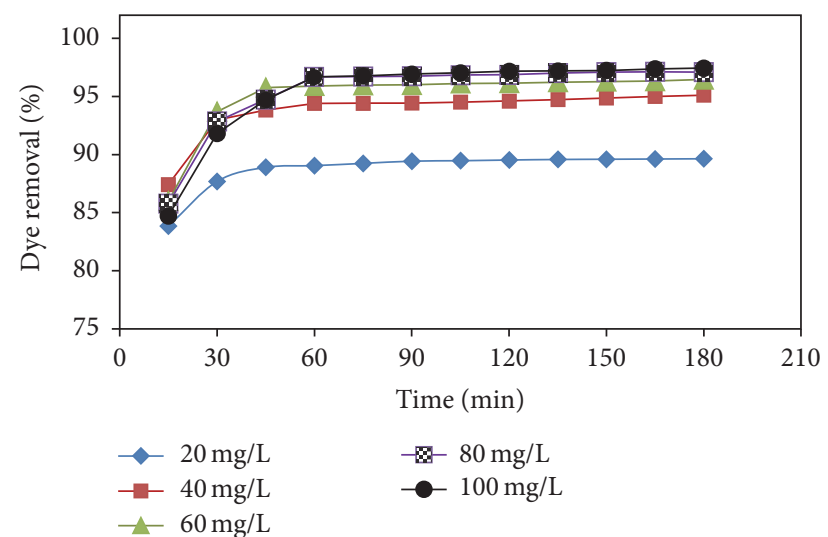

FIGURE 9: Effect of contact time on the removal of RR-RB dye in the presence of RB-5 dye (binary system) $\left(\right.$ temp. $=25^{\circ} \mathrm{C}$, speed $=$ $200 \mathrm{rpm}$, dose $=0.1 \mathrm{~g} / 100 \mathrm{~mL}$, and con. of RR-RB = con. of RB-5).

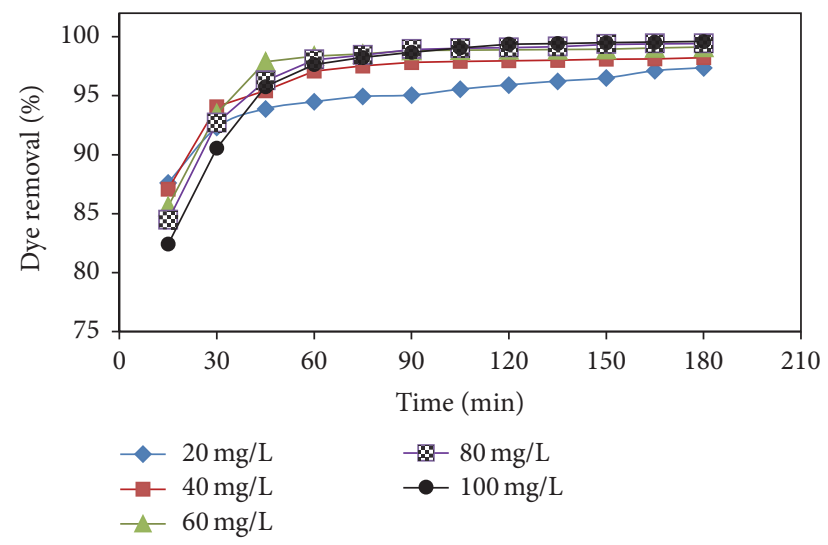

FIGURE 10: Effect of contact time on the removal of RB-5 dye in the presence of RR-RB dye (binary system) (temp. $=25^{\circ} \mathrm{C}$, speed $=$ $200 \mathrm{rpm}$, dose $=0.1 \mathrm{~g} / 100 \mathrm{~mL}$, and con. of RR-RB = con. of RB-5).

TABLE 4: Langmuir isotherm constants for RB-5 and RR-RB in binary system.

\begin{tabular}{lcccc}
\hline \multirow{2}{*}{ Dye in binary system } & \multicolumn{4}{c}{ Langmuir constants } \\
& $q_{\max }(\mathrm{mg} / \mathrm{g})$ & $b(\mathrm{~L} / \mathrm{mg})$ & $K_{L}(\mathrm{~L} / \mathrm{g})$ & $R^{2}$ \\
\hline RB-5 & 142.86 & 2.414 & 344.83 & 0.9912 \\
RR-RB & 116.3 & 0.18 & 20.8 & 0.9929 \\
\hline
\end{tabular}

are the maximum adsorption capacities from the Langmuir isotherm of dyes 1 and 2 in single dyes system. $b_{1}, b_{2}$ are the Langmuir isotherm constants for single dyes systems.

Consequently, for the binary system of RR-RB and RB5 dyes the extended Langmuir equation (after replacing the values of a parameter from Table 3 ) will become

$$
\begin{aligned}
q_{e, \mathrm{RB}-5} & =\frac{270.3 * 0.9024 C_{e, \mathrm{RB}-5}}{1+0.9024 C_{e, \mathrm{RB}-5}+0.444 C_{e, \mathrm{RR}-\mathrm{RB}}} \\
q_{e, \mathrm{RR}-\mathrm{RB}} & =\frac{169.5 * 0.444 C_{e, \mathrm{RR}-\mathrm{RB}}}{1+0.9024 C_{e, \mathrm{RB}-5}+0.444 C_{e, \mathrm{RR}-\mathrm{RB}}} .
\end{aligned}
$$

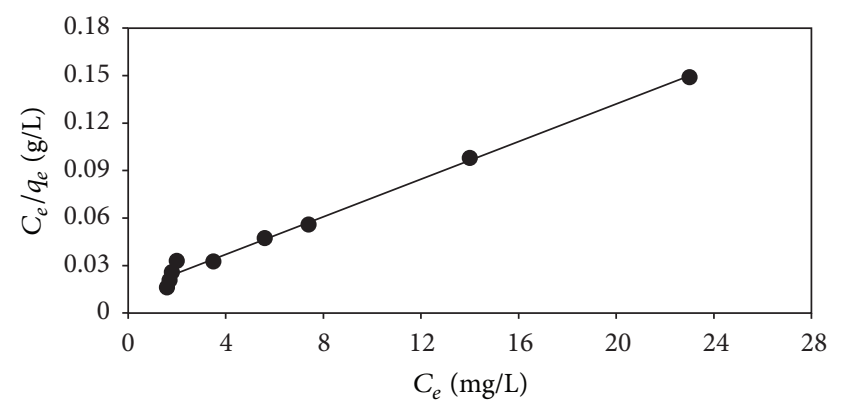

FIGURE 11: Langmuir adsorption isotherm of RR-RB onto QKCF (temp. $=25^{\circ} \mathrm{C}$, agitation speed $=200 \mathrm{rpm}$, time $=24 \mathrm{hr}$., and initial dye concentration $=100 \mathrm{mg} / \mathrm{L}$ ).

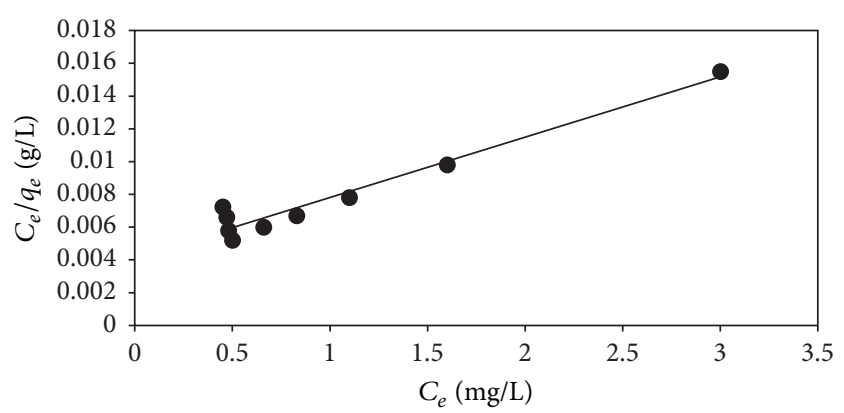

FIGURE 12: Langmuir adsorption isotherm of RB-5 onto QKCF (temp. $=25^{\circ} \mathrm{C}$, agitation speed $=200 \mathrm{rpm}$, time $=24 \mathrm{hr}$., and initial dye concentration $=100 \mathrm{mg} / \mathrm{L}$ ).

To evaluate the best fitted isotherm model, the sum of the squares of the errors (SSE), (17) was used to calculate the divergence of each isotherm model from experimental data [30].

$$
\sum_{i=1}^{n}\left(q_{\exp }-q_{\mathrm{cal}}\right)^{2}
$$

Figures 13 and 14 show the extended Langmuir equation applicable for the adsorption of RB-5 and RR-RB in the binary system. The sum of the squares errors for the correlation between the experimental data and that predicted by the extended Langmuir isotherm for RB-5 and RR-RB in binary system are 6386 and 1425, respectively. Moreover there are significant differences between calculated and experimental data which were observed, which indicate that extended Langmuir equation failed to explain the adsorption of the binary mixture of RR-RB and RB-5 dyes on the QKCF adsorbent. The failure of the model suggested that the binary adsorption might be competitive.

3.6.2. Jain and Snoeyink Modified (JSM) Extended Langmuir Model. According to Jain and Snoeyink [31], the Langmuir theory for binary adsorbed system is based on sorption without competition. Therefore, in order to compute for competition in the Langmuir theory, the Jain and Snoeyink 


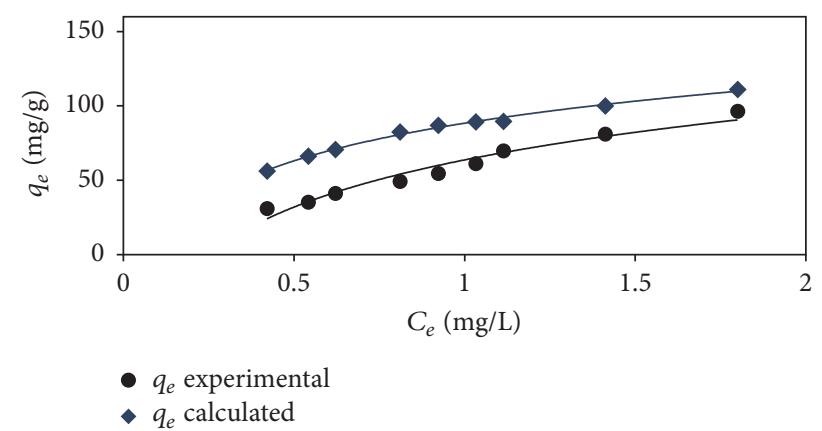

FIGURE 13: Extended Langmuir model for RB-5 in binary system with RR-RB (temp. $=25^{\circ} \mathrm{C}$, speed $=200 \mathrm{rpm}$, time $=24 \mathrm{hr}$., and con. of RR-RB = con. of RB-5 = $100 \mathrm{mg} / \mathrm{L}$ ).

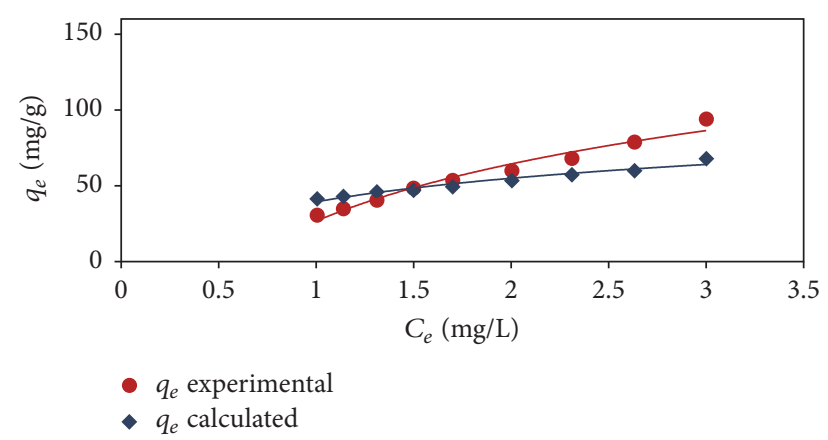

FIGURE 14: Extended Langmuir model for RR-RB in binary system with RB-5 (temp. $=25^{\circ} \mathrm{C}$, speed $=200 \mathrm{rpm}$, time $=24 \mathrm{hr}$., and con. of RR-RB = con. of RB-5 = $100 \mathrm{mg} / \mathrm{L}$ ).

model offered to add an additional term into (13) to become (18).

$$
\begin{aligned}
& q_{1}=\frac{\left(q_{\max , 1}-q_{\max , 2}\right) b_{1} C_{e, 1}}{1+b_{1} C_{e, 1}}+\frac{q_{\max , 2} b_{1} C_{e, 1}}{1+b_{1} C_{e, 1}+b_{2} C_{e, 2}} \\
& q_{2}=\frac{q_{\max , 2} b_{2} C_{e, 2}}{1+b_{1} C_{e, 1}+b_{2} C_{e, 2}} .
\end{aligned}
$$

The first term on the right-side of (18) is the Langmuir expression for the number of molecules of dye 1 that sorb without competition on the surface area of the adsorbent and the term is proportional to $\left(q_{\max , 1}-q_{\max , 2}\right)$, where $q_{\max , 1}>$ $q_{\max , 2}$, while the second term gives the amount of dye 1 adsorbed in competition with a second dye.

Figures 15 and 16 indicate the comparison between experimental data and predicted data by the Jain and Snoeyink modified extended Langmuir model. Figure 15 refers to disagreement between the model prediction and the experimental data with a sum of the squares errors equal to 14235 for RB-5, which is higher than that obtained from extended Langmuir equation. On the other hand, the sum of the squared errors between the prediction data and experimental data for RR-RB was 1425 .

Overall, although the extended Langmuir model was failed to describe the data in the binary system, it is better

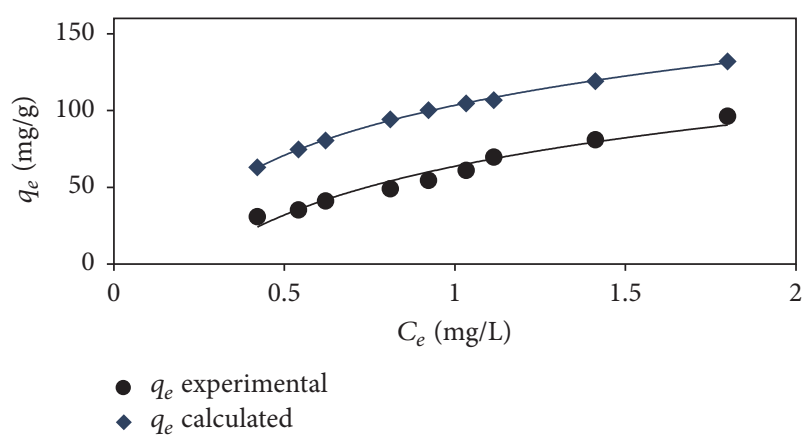

FIGURE 15: Jain and Snoeyink model for RB-5 in binary system with RR-RB (temp. $=25^{\circ} \mathrm{C}$, speed $=200 \mathrm{rpm}$, time $=24 \mathrm{hr}$., and con. of $\mathrm{RR}-\mathrm{RB}=$ con. of RB-5 = $100 \mathrm{mg} / \mathrm{L}$ ).

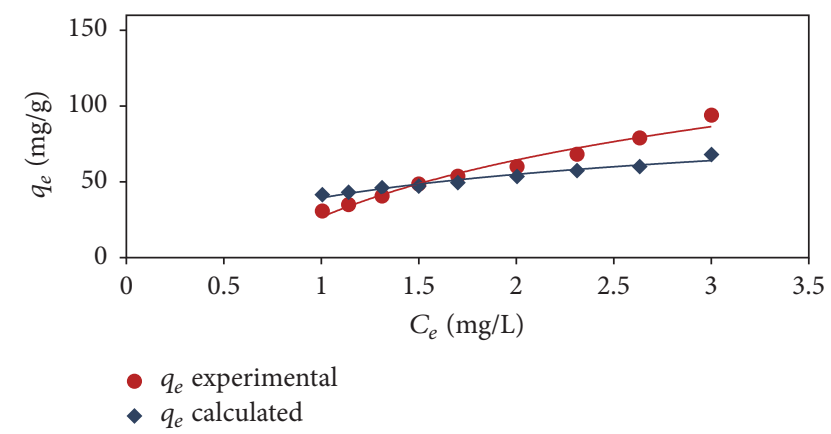

FIGURE 16: Jain and Snoeyink model for RR-RB in binary system with RB-5 (temp. $=25^{\circ} \mathrm{C}$, speed $=200 \mathrm{rpm}$, time $=24 \mathrm{hr}$, and con. of $\mathrm{RR}-\mathrm{RB}=$ con. of RB-5 = $100 \mathrm{mg} / \mathrm{L}$ ).

to represent the binary system than the Jain and Snoeyink modified extended Langmuir model.

3.7. Adsorption Kinetics Models for Dyes in Binary System. Kinetics adsorption study provides information about the mechanism of adsorption and also important for the qualification of the adsorption process [32]. It is important to define the average of adsorption during removing dyes from aqueous solution to optimize the design parameters because the kinetics of the system controls the adsorbate residence time and reactor dimensions. As a result, predicting the rate at which adsorption takes a place for any system is may be the most important factor in adsorption system design [33].

In order to analysis the experimental data for adsorption kinetics of RB-5 and RR-RB onto QKCF, the pseudo-firstorder and pseudo-second-order models were utilized. Equation (20) was used to describe the linear form of the pseudofirst-order model [34].

$$
\log \left(q_{e}-q_{t}\right)=\log q_{e}-\frac{K_{1}}{2.303} t
$$

where $q_{e}$ and $q_{t}$ are the amounts of dye adsorbed on adsorbent at equilibrium and at time $t$, respectively $(\mathrm{mg} / \mathrm{g})$, $t$ is the contact time (min), and $K_{1}$ is the rate constant of pseudo-first-order model ( $1 / \mathrm{min})$.

The values of constant $K_{1}$ and calculated $q_{e}$ were obtained from the slope and intercept, respectively, of plots 


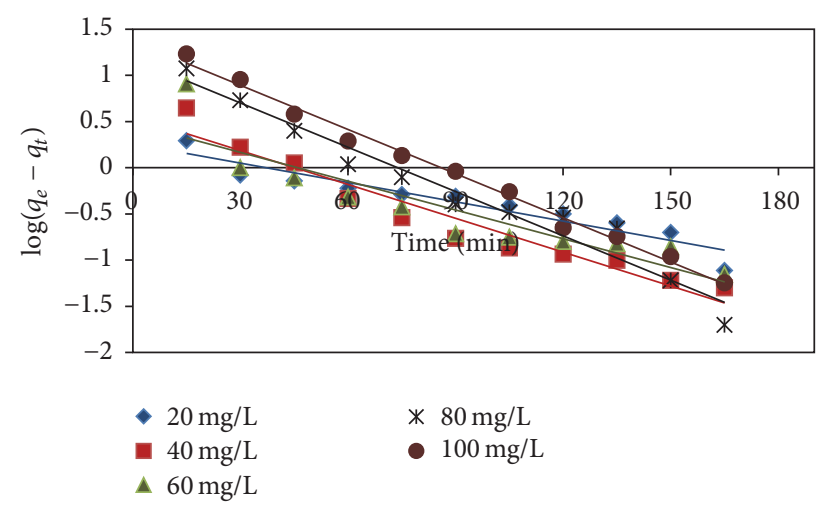

FIGURE 17: Pseudo-first-order kinetic model for adsorption RB-5 in binary system with RR-RB (temp. $=25^{\circ} \mathrm{C}$, speed $=200 \mathrm{rpm}$, dose $=$ $0.1 \mathrm{~g} / 100 \mathrm{~mL}$, and con. of RR-RB = con. of RB-5).

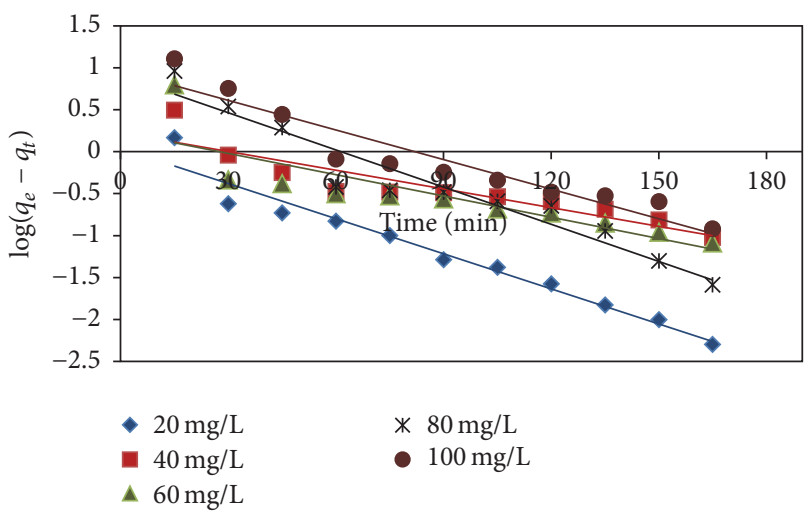

Figure 18: Pseudo-first-order kinetic model for adsorption RR-RB in binary system with RB-5 (temp. $=25^{\circ} \mathrm{C}$, speed $=200 \mathrm{rpm}$, dose $=$ $0.1 \mathrm{~g} / 100 \mathrm{~mL}$, and con. of RR-RB = con. of RB-5).

$\log \left(q_{e}-q_{t}\right)$ versus time $(t)$ as shown in Figures 17 and 18. The parameters and correlation coefficient $\left(R^{2}\right)$ of pseudofirst-order kinetic model were listed in Table 5. It clear from Table 5 that the calculated $q_{e}$ values for two dyes and for all concentration did not agree with experimental $q_{e}$ values; thus the pseudo-first-order model did not fit well for the experimental data. In recent years, the pseudo-second-order model has been widely used to descript the adsorption of dyes from aqueous solutions. Pseudo-second-order model (21) had been achieved by plotting $t / q_{t}$ versus time $(t)$ [35].

$$
\frac{t}{q_{t}}=\frac{1}{K_{2} q_{e}^{2}}+\frac{1}{q_{e}} t
$$

where $q_{e}(\mathrm{mg} / \mathrm{g})$ is the equilibrium adsorption capacity and $K_{2}(\mathrm{mg} / \mathrm{g} \mathrm{min})$ is the equilibrium rate constant of pseudosecond-order adsorption.

The values of $K_{2}$ and calculated $q_{e}$ can be fined from the slope and intercept of a plot of $t / q_{t}$ versus time $(t)$ as shown in Figures 19 and 20. The parameters and correlation coefficient $\left(R^{2}\right)$ of pseudo-second-order kinetic model were listed in Table 5. From Table 5, it can be seen that the correlation coefficients $R^{2}$ are ranging from 0.9999 to 1 and

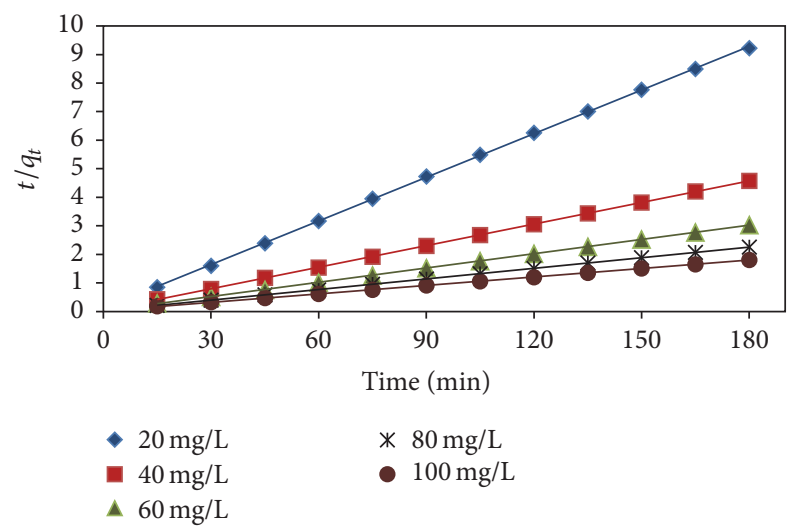

FIGURE 19: Pseudo-second-order kinetic model for adsorption RB-5 in binary system with RR-RB (temp. $=25^{\circ} \mathrm{C}$, speed $=200 \mathrm{rpm}$, dose $=0.1 \mathrm{~g} / 100 \mathrm{~mL}$, and con. of RR-RB = con. of RB-5).

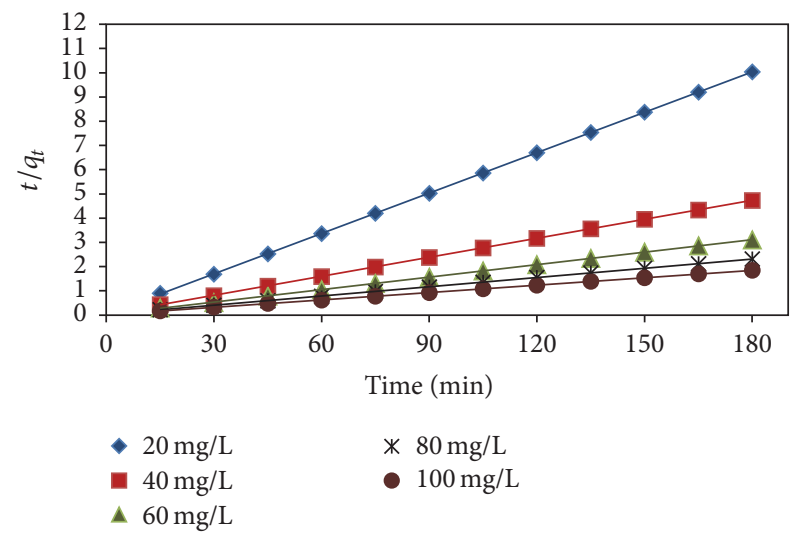

FIGURE 20: Pseudo-second-order kinetic model for adsorption RR$\mathrm{RB}$ in binary system with RB-5 (temp. $=25^{\circ} \mathrm{C}$, speed $=200 \mathrm{rpm}$, dose $=0.1 \mathrm{~g} / 100 \mathrm{~mL}$, and con. of RR-RB = con. of RB-5).

the calculated $q_{e}$ values are in agreement with experimental $q_{e}$ values. This indicates that the pseudo-second-order model provided the best correlation with experimental data. Hence, the adsorption kinetic of RB-5 and RR-RB on QKCF occurred by chemisorption and internal diffusion mechanism based on the assumption in the pseudo-second-order kinetic model [36].

\section{Conclusions}

The results of adsorption RR-RB and RB-5 dyes in binary system showed that QKCF can be effectively used as a bioadsorbent for the removal of anionic dyes. The QKCF bioadsorbent shows high sorption capacities toward RR-RB and RB-5. The kinetic studies stated that the adsorption kinetics of dyes on QKCF followed the pseudo-secondorder model at different dye concentrations. According to the present study, one could conclude that the QKCF is an effective adsorbent for anionic dyes removal from coloured textile wastewater. 
TABLE 5: Parameters and correlation coefficient $\left(R^{2}\right)$ for pseudo-first-order and pseudo-second-order kinetic models for adsorption RB-5 and RR-RB by QKCF in binary system.

\begin{tabular}{|c|c|c|c|c|c|c|c|c|}
\hline \multirow{2}{*}{$\begin{array}{l}\text { Dye in binary } \\
\text { system }\end{array}$} & \multirow{2}{*}{$\begin{array}{l}\text { Initial dye concentration } \\
(\mathrm{mg} / \mathrm{L})\end{array}$} & \multirow{2}{*}{$\begin{array}{c}q_{e} \exp \\
(\mathrm{mg} / \mathrm{g})\end{array}$} & \multicolumn{3}{|c|}{ Pseudo-first-order kinetic model } & \multicolumn{3}{|c|}{ Pseudo-second-order kinetic model } \\
\hline & & & $q_{e \mathrm{cal}}$ & $K_{1}$ & $R^{2}$ & $q_{e}$ cal. & $K_{2}$ & $R^{2}$ \\
\hline \multirow{5}{*}{ RB-5 } & 20 & 19.5 & 1.83 & 0.01612 & 0.91 & 19.6 & 0.023 & 0.9999 \\
\hline & 40 & 39.3 & 3.57 & 0.028 & 0.9384 & 39.68 & 0.0157 & 1 \\
\hline & 60 & 59.5 & 3.02 & 0.024 & 0.8213 & 59.88 & 0.0133 & 0.9999 \\
\hline & 80 & 79.54 & 15.22 & 0.037 & 0.957 & 80.6 & 0.0055 & 1 \\
\hline & 100 & 99.6 & 23.56 & 0.037 & 0.9812 & 101 & 0.0035 & 0.9999 \\
\hline \multirow{5}{*}{ RR-RB } & 20 & 17.93 & 1.1 & 0.032 & 0.959 & 18.02 & 0.081 & 1 \\
\hline & 40 & 38.1 & 1.68 & 0.017 & 0.833 & 38.3 & 0.025 & 1 \\
\hline & 60 & 57.88 & 1.71 & 0.0196 & 0.711 & 58.14 & 0.0189 & 1 \\
\hline & 80 & 77.73 & 8.1 & 0.0341 & 0.928 & 78.7 & 0.0084 & 1 \\
\hline & 100 & 97.5 & 9.22 & 0.0272 & 0.901 & 99 & 0.0055 & 1 \\
\hline
\end{tabular}

\section{Conflicts of Interest}

The authors declare that there is no conflict of interests regarding the publication of this paper.

\section{References}

[1] R. Kant, "Textile dyeing industry an environmental hazard," Natural Science, vol. 4, no. 1, pp. 22-26, 2012.

[2] X.-C. Jin, G.-Q. Liu, Z.-H. Xu, and W.-Y. Tao, "Decolorization of a dye industry effluent by Aspergillus fumigatus XC6," Applied Microbiology and Biotechnology, vol. 74, no. 1, pp. 239-243, 2007.

[3] M. Meneses, H. Concepción, D. Vrecko, and R. Vilanova, "Life cycle assessment as an environmental evaluation tool for control strategies in wastewater treatment plants," Journal of Cleaner Production, vol. 107, pp. 653-661, 2015.

[4] D. Shuchismita and I. Ashraful, "A review on textile wastewater characterization in Bangladesh," Resources and Environment, vol. 5, pp. 2163-2618, 2015.

[5] D. V. Nirmala, P. Saraswathi, and M. Makeswari, "Removal of dyes and heavy metals from aqueous soultion using ricinus communis as an adsorbent-a review," European Journal of Pharmaceutical and Medical Research (EJPMR), vol. 3, pp. 395398, 2016

[6] G. Z. Kyzas and M. Kostoglou, "Green adsorbents for wastewaters: a critical review," Materials, vol. 7, no. 1, pp. 333-364, 2014.

[7] M. R. Mafra, L. Igarashi-Mafra, D. R. Zuim, É. C. Vasques, and M. A. Ferreira, "Adsorption of remazol brilliant blue on an orange peel adsorbent," Brazilian Journal of Chemical Engineering, vol. 30, no. 3, pp. 657-665, 2013.

[8] C. K. Lee, S. T. Ong, and Z. Zainal, "Ethylenediamine modified rice hull as a sorbent for the removal of Basic Blue 3 and Reactive Orange 16," International Journal of Environment and Pollution, vol. 34, no. 1-4, pp. 246-260, 2008.

[9] A. A. Oladipo, M. Gazi, and E. Yilmaz, "Single and binary adsorption of azo and anthraquinone dyes by chitosan-based hydrogel: selectivity factor and Box-Behnken process design," Chemical Engineering Research and Design, vol. 104, pp. 264279, 2015.

[10] K. A. Adegoke and O. S. Bello, "Dye sequestration using agricultural wastes as adsorbents," Water Resources and Industry, vol. 12, pp. 8-24, 2015.
[11] P. Nigam, G. Armour, I. M. Banat, D. Singh, and R. Marchant, "Physical removal of textile dyes from effluents and solidstate fermentation of dye-adsorbed agricultural residues," Bioresource Technology, vol. 72, no. 3, pp. 219-226, 2000.

[12] M. Chaudhuri, E. S. Elmolla, and R. B. Othman, "Adsorption of reactive dyes Remazol red F-3B and Remazol blue from aqueous solution by coconut coir activated carbon," Nature Environment and Pollution Technology, vol. 10, no. 2, pp. 193-196, 2011.

[13] M. M. Nourouzi, T. G. Chuah, and T. S. Y. Choong, "Equilibrium and kinetic study on reactive dyes adsorption by palm kernel shell-based activated carbon: in single and binary systems," Journal of Environmental Engineering, vol. 135, no. 12, pp. 13931398, 2009.

[14] S. Y. Wong, Y. P. Tan, A. H. Abdullah, and T. S. Ong, "The removal of basic and reactive dyes using quartenised sugar cane bagasse," Journal of Physical Science, vol. 20, no. 1, pp. 59-74, 2009.

[15] S.-T. Ong, W.-N. Lee, P.-S. Keng, S.-L. Lee, Y.-T. Hung, and S.-T. Ha, "Equilibrium studies and kinetics mechanism for the removal of basic and reactive dyes in both single and binary systems using EDTA modified rice husk," International Journal of Physical Sciences, vol. 5, no. 5, pp. 582-595, 2010.

[16] H. S. Abbas, M. A. Waleed, J. Tariq, and F. A. Dhafer, "Single and binary adsorption of reactive blue and red dyes onto activated carbon," International Journal of Engineering Innovation and Research, vol. 3, no. 5, pp. 642-649, 2014.

[17] S. Hajati, M. Ghaedi, F. Karimi, B. Barazesh, R. Sahraei, and A. Daneshfar, "Competitive adsorption of Direct Yellow 12 and Reactive Orange 12 on ZnS:Mn nanoparticles loaded on activated carbon as novel adsorbent," Journal of Industrial and Engineering Chemistry, vol. 20, no. 2, pp. 564-571, 2014.

[18] I. A. W. Tan, A. L. Ahmad, and B. H. Hameed, "Adsorption of basic dye using activated carbon prepared from oil palm shell: batch and fixed bed studies," Desalination, vol. 225, no. 1-3, pp. 13-28, 2008.

[19] E. Ekrami and M. Okazi, "Analysis of dye concentration in binary dye solutions using derivative spectrophotometric techniques," World Applied Science Journal, vol. 11, no. 8, pp. 10251034, 2010.

[20] D. V. Pavia, G. M. Lampman, G. S. Kriz, and J. R. Vyvyan, Introduction to Spectroscopy, Brooks Cole Publishing, Pacific Grove, Calif, USA, 4th edition, 2009. 
[21] K. Nakagawa, A. Namba, S. R. Mukai, H. Tamon, P. Ariyadejwanich, and W. Tanthapanichakoon, "Adsorption of phenol and reactive dye from aqueous solution on activated carbons derived from solid wastes," Water Research, vol. 38, no. 7, pp. 1791-1798, 2004.

[22] R. N. Ibbett, S. Kaenthong, D. A. S. Phillips, and M. A. Wilding, "Characterisation of the porosity of regenerated cellulosic fibres using classical dye adsorption techniques," Lenzinger Berichte, vol. 85, pp. 77-86, 2006.

[23] Y. Safa and H. N. Bhatti, "Kinetic and thermodynamic modeling for the removal of direct red-31 and direct orange-26 dyes from aqueous solutions by rice husk," Desalination, vol. 272, no. 1-3, pp. 313-322, 2011.

[24] Sumanjit, Seema, R. K. Mahajan, and V. K. Gupta, "Modification of surface behaviour of Eichhornia crassipes using surface active agent: an adsorption study," Journal of Industrial and Engineering Chemistry, vol. 21, pp. 189-197, 2015.

[25] K. Shakir, A. F. Elkafrawy, H. F. Ghoneimy, S. G. Elrab Beheir, and M. Refaat, "Removal of rhodamine B (a basic dye) and thoron (an acidic dye) from dilute aqueous solutions and wastewater simulants by ion flotation," Water Research, vol. 44, no. 5, pp. 1449-1461, 2010.

[26] E. Demirbas and M. Z. Nas, "Batch kinetic and equilibrium studies of adsorption of Reactive Blue 21 by fly ash and sepiolite," Desalination, vol. 243, no. 1-3, pp. 8-21, 2009.

[27] R. R. Bansode, Treatment of organic and inorganic pollutants in municipal wastewater by agricultural by-product based granular activated carbons (GAC) [M.S. thesis], Louisiana State University, Agricultural and Mechanical College, the Department of Food Science, 2002.

[28] P. K. Malik, "Dye removal from wastewater using activated carbon developed from sawdust: adsorption equilibrium and kinetics," Journal of Hazardous Materials, vol. 113, no. 1-3, pp. 81-88, 2004.

[29] J. A. V. Butler and C. Ockrent, "Studies in electrocapillarity. Part III: the surface tensions of solutions containing two surfaceactive solutes," Journal of Physical Chemistry, vol. 34, no. 12, pp. 2841-2859, 1930.

[30] K. V. Kumar and S. Sivanesan, "Comparison of linear and nonlinear method in estimating the sorption isotherm parameters for safranin onto activated carbon," Journal of Hazardous Materials, vol. 123, no. 1-3, pp. 288-292, 2005.

[31] J. S. Jain and V. L. Snoeyink, "Adsorption from bisolute systems on active carbon," Journal of the Water Pollution Control Federation, vol. 45, no. 12, pp. 2463-2479, 1973.

[32] N. M. Mahmoodi, "Equilibrium, kinetics, and thermodynamics of dye removal using alginate in binary systems," Journal of Chemical and Engineering Data, vol. 56, no. 6, pp. 2802-2811, 2011.

[33] Y.-S. Ho, "Review of second-order models for adsorption systems," Journal of Hazardous Materials, vol. 136, no. 3, pp. 681689, 2006.

[34] S. Azizian, "Kinetic models of sorption: a theoretical analysis," Journal of Colloid and Interface Science, vol. 276, no. 1, pp. 47-52, 2004.

[35] A. E. Nemr, "Potential of pomegranate husk carbon for Cr(VI) removal from wastewater: kinetic and isotherm studies," Journal of Hazardous Materials, vol. 161, no. 1, pp. 132-141, 2009.

[36] J. S. Piccin, C. S. Gomes, L. A. Feris, and M. Gutterres, "Kinetics and isotherms of leather dye adsorption by tannery solid waste," Chemical Engineering Journal, vol. 183, pp. 30-38, 2012. 


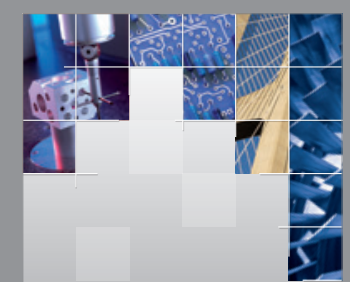

\section{Enfincering}
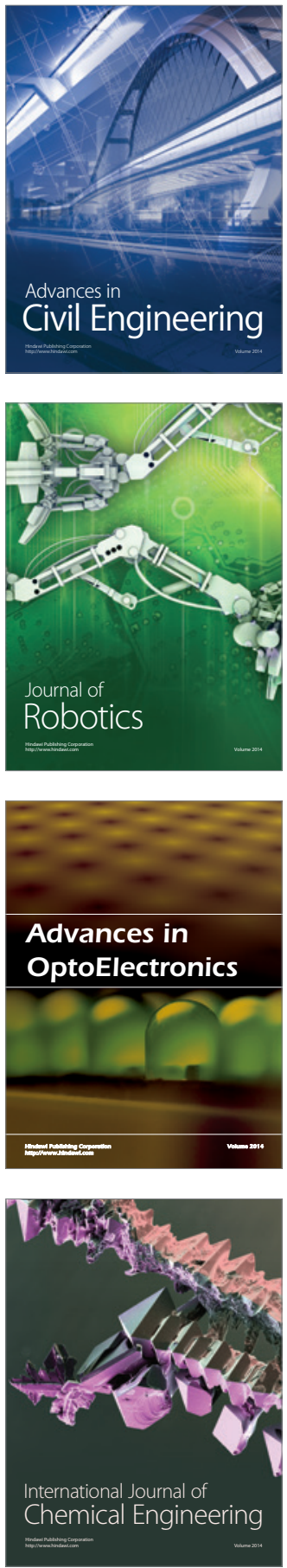

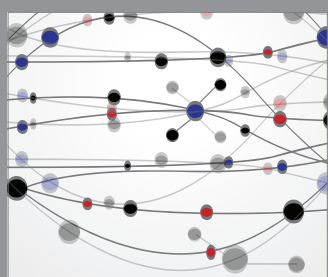

The Scientific World Journal

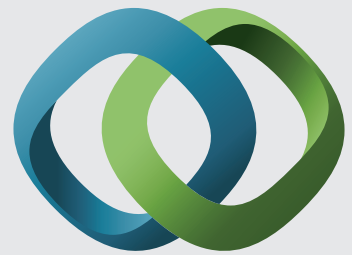

\section{Hindawi}

Submit your manuscripts at

https://www.hindawi.com
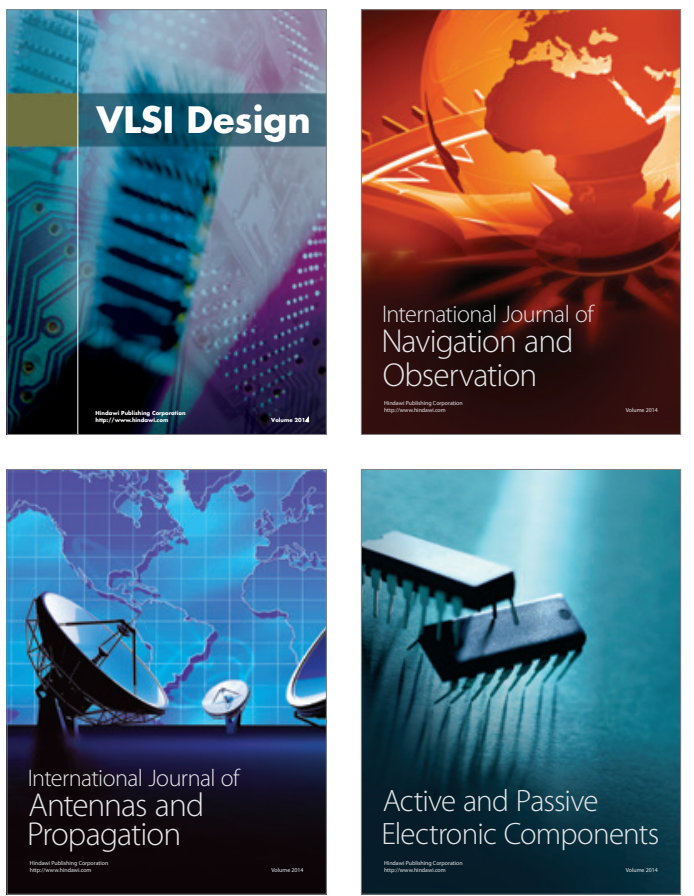
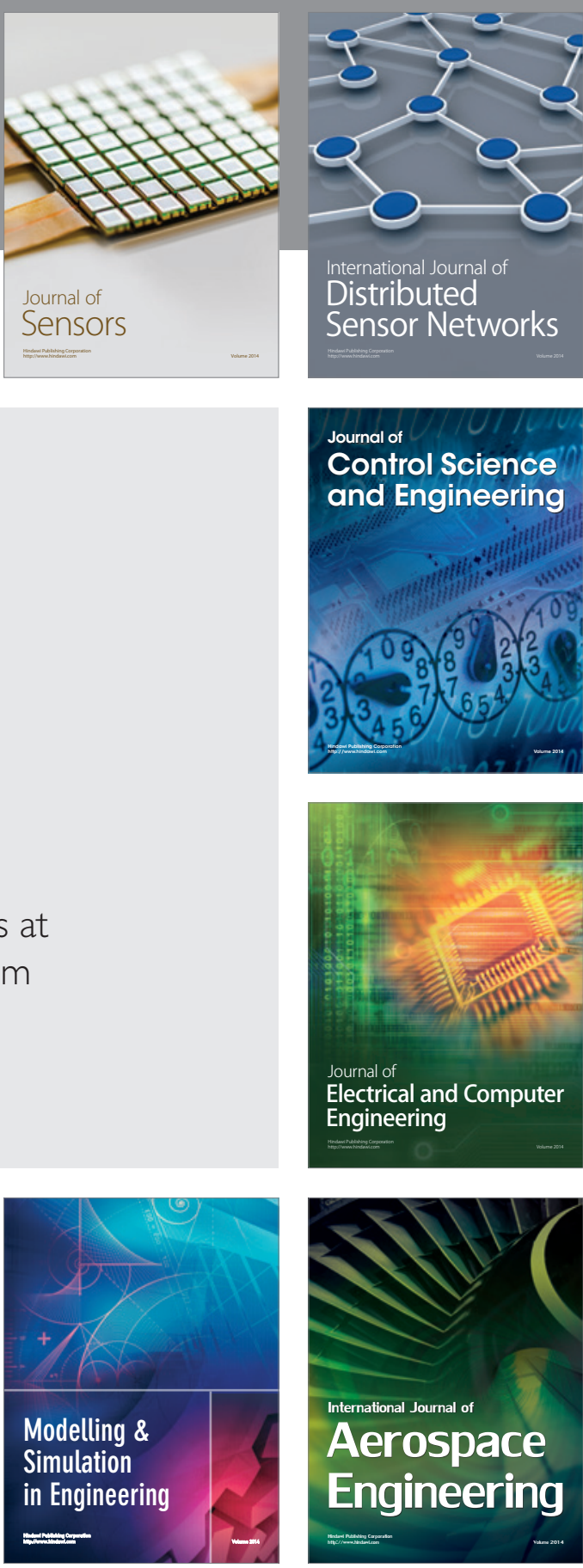

International Journal of

Distributed

Sensor Networks

$-$

Joumal of

Control Science

and Engineering
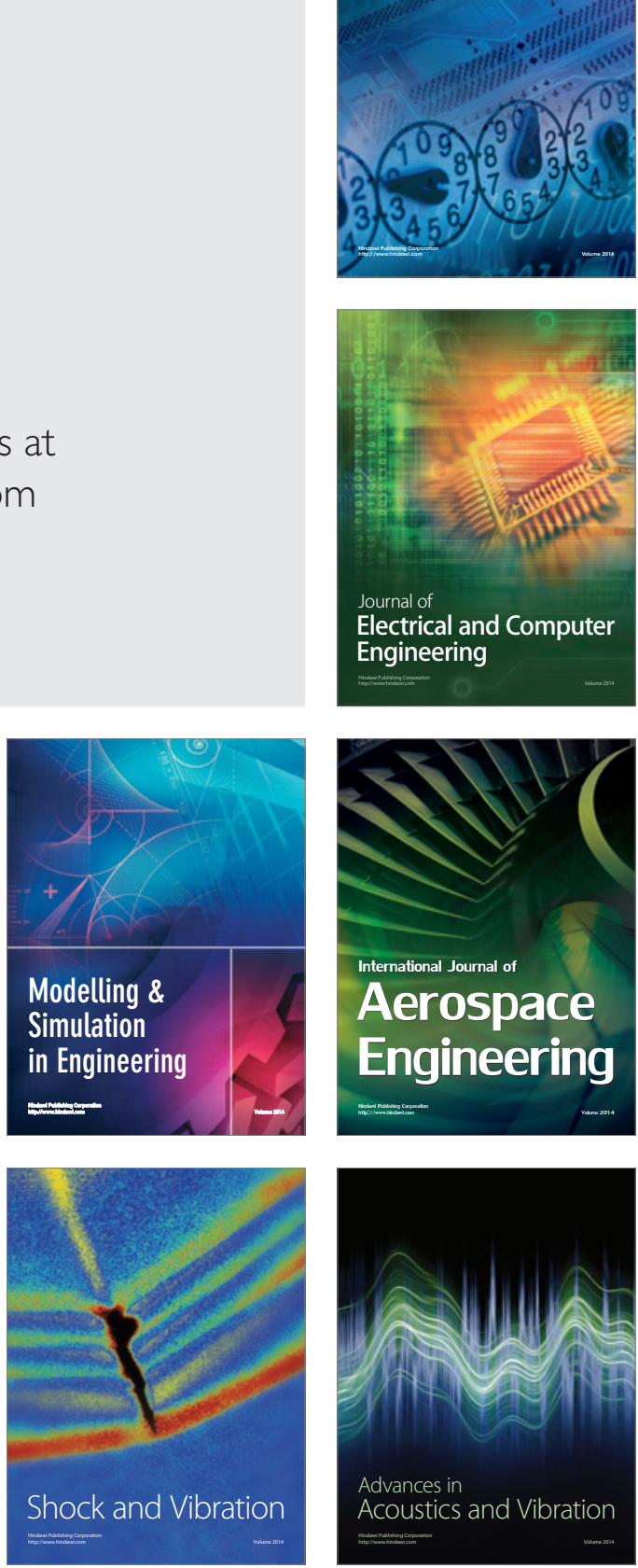